LBNL-58254

\title{
Potential Benefits from Improved Energy Efficiency of Key Electrical Products: The Case of India
}

\author{
Michael McNeil, Maithili Iyer, Stephen Meyers, \\ Virginie Letschert, James E. McMahon \\ Environmental Energy Technologies Division \\ Lawrence Berkeley National Laboratory \\ University of California, Berkeley \\ Berkeley, CA
}

December 2005

This work was supported by the International Copper Association through the U.S. Department of Energy under Contract No. DE-AC03-76SF00098. 


\begin{abstract}
The goal of this project was to estimate the net benefits that cost-effective improvements in energy efficiency can bring to developing countries. The study focused on four major electrical products in the world's second largest developing country, India. These products - refrigerators, room air conditioners, electric motors, and distribution transformers - are important targets for efficiency improvement in India and in other developing countries. India is an interesting subject of study because of it's size and rapid economic growth. Implementation of efficient technologies in India would save billions in energy costs, and avoid hundreds of megatons of greenhouse gas emissions. India also serves as an example of the kinds of improvement opportunities that could be pursued in other developing countries.
\end{abstract}




\section{Table of Contents}

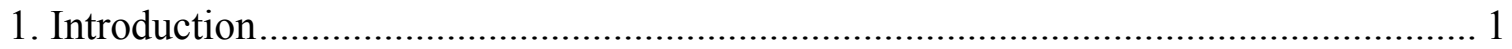

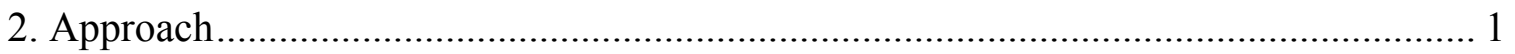

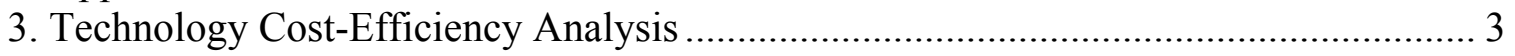

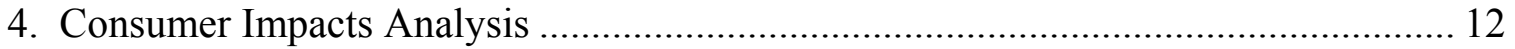

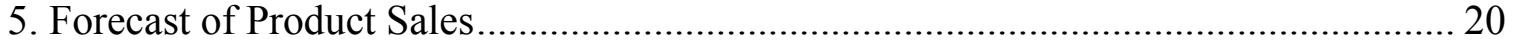

6. National Impacts of the High Efficiency Case ......................................................... 24

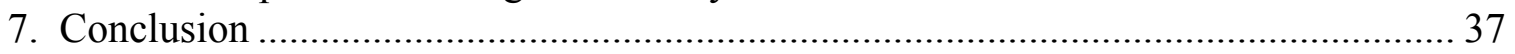

Appendix A Calculating Marginal Electricity Rates ............................................... 42

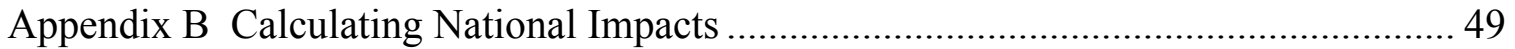

Appendix C Primary Energy and Emissions for Indian Power Sector .......................... 51 


\section{Introduction}

The goal of this project was to estimate the net benefits that cost-effective improvements in energy efficiency can bring to developing countries. The study focuses on four major electrical products in the world's second largest developing country, India. These products - refrigerators, room air conditioners, electric motors, and distribution transformers - are important targets for efficiency improvement in India and in other developing countries.

India is a major energy consumer. Its energy consumption growth is rapid and continual. Efficiency policies have a particularly important role to play since so much new equipment is entering the stock. Cost-effective efficiency measures will save consumers money, but they also address other important issues as well. India is currently unable to generate enough electricity to meet demand. To do so, it will have to expend capital to increase generation capacity and reduce system losses. Improved efficiency has the additional benefits of increasing the number of customers served by existing generation and reducing the investment necessary to meet demand.

While India is unique, many aspects related to efficiency there are common to other developing countries. In many countries, economic growth will drive energy demand through increases in energy-intensive industrial production, growth of the service sector, and entry of an increasing number of people to a level of income that allows for ownership of major energy-consuming appliances. Building the generation capacity necessary to meet this demand is a continuing concern throughout the developing world.

This report estimates potential efficiency savings for a few important products. Thus, the estimated benefits represent only a part of the total that might be realized through a comprehensive program of efficiency improvement applied to a larger set of energyusing products. Our focus is to provide the most specific and technically accurate analysis available. For this reason, we do not consider likely opportunities where solid technical data is not yet available.

\section{Approach}

The study combines a bottom-up engineering-economic analysis of specific technologies with a projection of the market evolution for each product.

\section{Technology Cost-Efficiency Analysis}

For each product, we first characterize key characteristics (including efficiency level) for specific product classes. Each product is represented by two or more product classes. For refrigerators, for example, we consider single-door manual defrost and two-door autodefrost models. We estimate the typical user purchase cost of each product class. The characteristics of the most common current product establish the baseline, for which we 
gather data on purchase price and energy-use characteristics. Efficiency improvements and their costs are estimated relative to this baseline.

We estimate the energy savings and additional purchase cost associated with specific technologies that enhance efficiency. The fundamental component of the purchase cost is the per-unit manufacturing cost. To this cost we apply markups for manufacturers and distributors that result in the purchase price.

Taking typical product utilization and equipment lifetime into account, we calculate the Life-Cycle Cost (LCC) of owning and operating a product at alternative efficiency levels for a typical user. The LCC accounts for the electricity costs paid by the consumer or, in the case of transformers, the costs of electricity generation. The price of the electricity that is saved at the margin is based on current tariff structures. Future prices are based on projections of electricity prices or avoided costs for product users.

We calculate LCC values using discount rates appropriate for each type of user. The typical user is a household in the case of refrigerators, a household or commercial enterprise for room air conditioners, an industrial firm or agricultural operation in the case of motors, and an electric utility in the case of transformers. We based the discount rates on Indian conditions.

For each product, we identify the efficiency level with the lowest LCC, which represents the most economically justifiable design for the consumer. Of course, policy makers will consider other factors besides consumer LCC in reaching their decisions about target efficiency levels, including impacts on manufacturers.

\section{Market Projection}

The approach for estimating the sales of each product for each year in the 2010-2020 period involves use of historical shipments data (for estimating replacement sales), sales forecasts by a market research firm, and consideration of the key drivers for growth of each product. For appliances in a growing market, new installations account for the majority of sales, rather than replacement of retired equipment.

\section{Potential National Impacts with High-Efficiency Products}

Our estimate of impacts considers the outcome if all products installed in the 2010-2020 period embody the identified cost-effective efficiency level. The benefits of this High Efficiency scenario are measured against a Base Case in which the efficiency of each product remains at current levels. This Base Case is not a forecast of what is likely to happen, as efficiency will likely improve to some degree due to market forces. Since the extent of this market-driven improvement is very uncertain, we chose not to incorporate estimates of such improvement in the Base Case.

The impacts for each year consider the accumulated stock of products sold in the 2010-20 period. We count impacts through 2030. 
We calculate the total benefit to consumers as the difference between total energy cost savings and additional first costs for higher-efficiency products in each year. Depending upon the product, we multiply the electricity savings in each year by the projected marginal electricity price for households or industries or commercial enterprises, or by the projected marginal price of electricity supply for utilities. To arrive at a cumulative benefit, we discount the net benefit or cost in each future year to the present using discount rates appropriate for each type of user.

In estimating national benefits, we consider impacts assuming that the current situation of electricity shortages is greatly relieved by 2010 (as envisioned by government plans). Thus, reduced electricity consumption from higher efficiency products does have an effect on generation at the margin. We calculate the present value of the net national benefits using an appropriate national discount rate for India.

We also consider how the benefits would differ if shortages continue in the 2010-2020 period. In this case, much of the electricity saved through higher efficiency could be sold to consumers whose demand would otherwise not be met. This consumption would allow for additional economic output or would provide services to households.

Based on savings of energy at the consumer level, we calculate the associated reduction in national electricity generation and primary energy consumption using estimates of future $T \& D$ losses and generating efficiency. We calculate the associated reduction in emissions of carbon dioxide based on per-kWh emissions factors.

\section{Technology Cost-Efficiency Analysis}

For each considered product, we estimated the incremental consumer cost of technologies providing higher energy efficiency relative to a specific baseline technology, as well as the associated reduction in annual energy use.

\section{Refrigerators}

There are two main product classes for residential refrigerators in India: direct cool (manual defrost) and frost-free. Nearly all of the direct-cool models are one-door type, with a small freezer compartment within the same cabinet area as the fresh-food compartment. Likewise, the frost-free units are entirely two-door units, with two isolated compartments connected by an air passage. Traditionally, direct cool units have dominated the market, but frost-free units are gaining ground. According to a recent survey of Indian refrigerator manufacturers (IMRB 2004), direct-cool units command $82 \%$ percent of the market, with $18 \%$ held by frost-free. One source indicates, however, that sales of frost-free units are currently growing at $20 \%$ per year. ${ }^{1}$

\footnotetext{
${ }^{1}$ STAT-USA Industry Sector Analysis - Refrigeration and Air Conditioning Equipment - India
} 
The parameters necessary to assess the cost effectiveness of improved refrigerator efficiency are taken from an engineering analysis (Bhatia 1999), which evaluated the characteristics of a baseline refrigerator model and utilized a simulation software package in order to determine efficiency benefits. This analysis used cost estimates reported by Indian refrigerator manufacturers.

Table 1 shows data collected for direct-cool refrigerators of 165-liter capacity. This capacity of refrigerator class continues to be the most popular sold. We assume that the relationship between cost increase and efficiency improvement is still generally applicable to the baseline unit on the market today.

In order to more accurately estimate energy savings of current Indian refrigerators, we estimated the daily electricity consumption from a survey of the current market (IMRB 2004). This dataset is comprehensive in terms of models currently sold, but does not have consumption data for many models. Therefore we adopt the methodology of a recent report (Harrington 2004), which estimated a compressor activation rate of $38 \%$ for Indian refrigerators currently on the market. Using this, in combination with the wattage ratings provided for current models (weighted by sales), we determine that the baseline refrigerator uses an average of $0.98 \mathrm{kWh}$ per day. Annual unit energy consumption for the baseline model is $0.98 \mathrm{kWh} /$ day $\times 365$ days $=359 \mathrm{kWh}^{2}$

Frost-free models, almost all of which are two-door models in India, are much more energy intensive. According to a sample of models tested by manufacturers, the average consumption of a frost-free model is roughly $2.4 \mathrm{kWh} /$ day, or $876 \mathrm{kWh}$ per year.

The incremental costs shown in the table represent direct material and labor expenses to the manufacturer, and are not indicative of the additional price paid by the consumer, which also includes distributor and retail markups. In order to estimate these, we scale the percentage manufacturer incremental costs according to an estimate of baseline retail price. The baseline retail price for a 165-liter direct-cool (single-door) refrigerator are taken from a survey of a comparison-shopping website in India (www.compareindia.com). Price data are from a sampling of retail outlets, and therefore we judge them to be competitive and potentially more representative of actual prices paid than manufacturers' suggested retail prices. The average of a sample of 17 models between 165 and 175 liters is $\$ 184$ at current exchange rates (45.45 Rs/\$).

\footnotetext{
${ }^{2}$ Although refrigerators may not be operational during every hour of the day due to unreliability of the power supply, we assume, however that any compressor run time lost during a power outage is compensated for by the increased cooling necessary when power is restored.
} 
Table 1. Efficiency Improvement and Incremental Manufacturer Cost for Refrigerator Design Options (direct-cool refrigerator of 165 liter capacity) ${ }^{3}$

\begin{tabular}{|c|c|c|c|c|c|c|c|c|c|}
\hline & \multirow{3}{*}{ Design } & \multicolumn{4}{|c|}{ Energy } & \multicolumn{2}{|c|}{$\begin{array}{c}\text { Manufacturer } \\
\text { Cost }\end{array}$} & \multicolumn{2}{|c|}{$\begin{array}{l}\text { Incremental } \\
\text { Price }\end{array}$} \\
\hline & & \multicolumn{2}{|c|}{ Unit Savings } & \multicolumn{2}{|c|}{ UEC } & $\Delta \operatorname{Cost}$ & Cum & Price & Cum \\
\hline & & kWh/day & $\%$ & kWh/day & $\mathrm{kWh} / \mathrm{yr}$ & $\$$ & $\%$ & & $\$$ \\
\hline 0 & Baseline & & & 0.98 & 359 & & & $\$ 184$ & $\$ 0.00$ \\
\hline 1 & $\begin{array}{c}\text { Gasket Heat Leak Reduction } \\
25 \% \\
\end{array}$ & 0.05 & $5 \%$ & 0.94 & 341 & $\$ 2$ & $1.3 \%$ & $\$ 186$ & $\$ 2.39$ \\
\hline 2 & Higher EER(4.13) compressor & 0.23 & $23 \%$ & 0.76 & 276 & $\$ 7$ & $3.9 \%$ & $\$ 191$ & $\$ 7.17$ \\
\hline 3 & in door and wall by $50 \%$ & 0.45 & $45 \%$ & 0.54 & 196 & $\$ 19$ & $10.3 \%$ & $\$ 203$ & $\$ 18.94$ \\
\hline 4 & $\begin{array}{c}\text { Increase Evaporator area by } \\
33 \%\end{array}$ & 0.46 & $47 \%$ & 0.52 & 190 & $\$ 23$ & $12.7 \%$ & $\$ 207$ & $\$ 23.36$ \\
\hline 5 & \begin{tabular}{|c} 
Increase condenser area by \\
$50 \%$
\end{tabular} & 0.49 & $50 \%$ & 0.49 & 179 & $\$ 32$ & $17.4 \%$ & $\$ 216$ & $\$ 32.00$ \\
\hline
\end{tabular}

For frost-free models, the baseline is around 220 liters, with about half of sales for units within the 220 to 250 liter range. To estimate the baseline price for frost-free models, we used a sample of 18 models from the same retail source, and found an average price of $\$ 311$ for units between 220-235 liters.

\section{Air conditioners}

As in the case of refrigerators, there are two main classes of room air conditioners common in India, but one of them dominates the market. Indian businesses and residences use both window-mounted and split air conditioning units, but window units enjoy $83 \%$ of production, according to a recent survey of air conditioner manufacturers(IMRB 2004). The market share of split units shows some indication of gaining ground on window units, however. Central air conditioning is still relatively rare in India.

Traditionally, large commercial enterprises dominated the purchase of air conditioning equipment, but residential consumers are entering the market. We estimate that by 2010, half of the purchases will be made by residential customers.

Detailed engineering data for air conditioners particular to the Indian market are not available as they were for refrigerators. Air conditioner designs tend to be similar among countries, however, so that design option parameters from the U.S. market may be used as a proxy.

\footnotetext{
${ }^{3}$ Baseline design assumed to have (1) Gasket heat leak rate of $8.0 \mathrm{~W} / \mathrm{m}-100^{\circ} \mathrm{C}$, (2) Compressor EER of 3.41, (3) Wall and door insulation thickness $4.00 \mathrm{~cm}$ (4) Evaporator area $0.488 \mathrm{~m}^{2}$ and (5) Condenser area $0.63 \mathrm{~m}^{2}$; from Bhatia (1999).
} 
Baseline capacity, retail price and efficiency are estimated from a combination of production data, and model data from www.compareindia.com. Market shares of each cooling capacity category are taken from manufacturer production estimates. The most common capacity class is 1.5 ton $(12,000 \mathrm{Btu} / \mathrm{hr})$ cooling capacity, with one and two-ton units making up most of the remainder of the market. The market-weighted average capacity is 1.5 tons, or $18,000 \mathrm{Btu} / \mathrm{hr}$, well within the range of the units covered in the product class analyzed for U.S. DOE minimum efficiency standards (Table 2). The market-weighted average price of the online models is $\$ 497$, and the average efficiency level (EER) is 9.1. Since the baseline efficiency considered by the DOE analysis was 9.0 EER, the average retail price of these models should be reasonably representative of the baseline price.

Table 2. Room Air Conditioners in India: Capacity, Retail Price and Efficiency

\begin{tabular}{|c|c|c|c|c|}
\hline Capacity (in Tons) & $\%$ Market & Price (Rs) & Price $(\$)$ & EER \\
\hline 0.75 & $0.1 \%$ & 12870 & $\$ 283$ & 9.2 \\
\hline 0.8 & $1.0 \%$ & 15725 & $\$ 346$ & 9.3 \\
\hline 1 & $10.3 \%$ & 20587 & $\$ 453$ & 8.7 \\
\hline 1.25 & $0.6 \%$ & 19993 & $\$ 440$ & 9.4 \\
\hline 1.5 & $78.3 \%$ & 22561 & $\$ 496$ & 9.3 \\
\hline 2 & $8.7 \%$ & 26045 & $\$ 573$ & 9.0 \\
\hline 2.2 & $0.1 \%$ & \multirow{3}{*}{\multicolumn{3}{|c|}{$\mathrm{N} / \mathrm{A}$}} \\
\hline 3 & $0.5 \%$ & & & \\
\hline 4 & $0.3 \%$ & & & \\
\hline \multicolumn{5}{|c|}{ Weighted Average } \\
\hline 1.50 & $99.9 \%$ & 22567 & $\$ 497$ & 9.1 \\
\hline
\end{tabular}

Table 3 shows the changes in EER and equipment cost estimated for various room AC efficiency levels in the U.S. DOE's analysis (USDOE 1997). The annual energy consumption in India is estimated using assumptions about utilization by residential and commercial users. ${ }^{4}$ The efficiency increase with design 1 implies a $7.2 \%$ reduction in energy consumption, reducing annual use from $1191 \mathrm{kWh}$ to $1105 \mathrm{kWh}$.

\footnotetext{
${ }^{4}$ The regions in India where AC is common (North) have a six month cooling season. We assume that commercial users (assuming these are mostly office buildings) use AC 8 hours a day, 20 days a month, and that residential users use AC 4 hours a day, 30 days a month. This gives 960 hours per year for commercial users, and 720 hours for residential. We assume that by 2010, residential sales (and therefore affected stock) will be equal to commercial, so we take a simple average and get 840 hours per year.
} 
Table 3. Efficiency Improvement and Incremental Manufacturer Cost for Window Air Conditioners With Louvered Sides - 14,000 to 19,999 Btu/hr Capacity

\begin{tabular}{|c|c|c|c|c|c|c|c|c|}
\hline \multirow{3}{*}{$\begin{array}{l}\text { Design } \\
\text { Number }\end{array}$} & \multirow{3}{*}{ Design } & \multirow{3}{*}{ EER } & \multicolumn{3}{|c|}{ Energy Savings } & \multicolumn{3}{|c|}{ Equipment Price } \\
\hline & & & \multicolumn{2}{|c|}{ Unit Savings } & \multirow{2}{*}{$\frac{\text { UEC }}{\mathrm{kWh} / \mathrm{yr}}$} & \multirow{2}{*}{$\begin{array}{c}\text { Inc. } \\
\%\end{array}$} & \multirow{2}{*}{\begin{tabular}{|r|} 
Total \\
$\$$
\end{tabular}} & \multirow[t]{2}{*}{ Delta } \\
\hline & & & $\mathrm{kWh} / \mathrm{yr}$ & $\%$ & & & & \\
\hline 0 & Baseline & 9.0 & & & 1191 & $0 \%$ & $\$ 497$ & $\$ 0$ \\
\hline 1 & $0+$ Incr Compressor EER to 10.8 & 9.7 & 86 & $7.2 \%$ & 1105 & $4 \%$ & $\$ 514$ & $\$ 17$ \\
\hline 2 & $1+$ Condenser Grooved Tubes & 10.0 & 117 & $9.8 \%$ & 1074 & $5 \%$ & $\$ 520$ & $\$ 24$ \\
\hline 3 & $2+$ Add Subcooler & 10.2 & 135 & $11.3 \%$ & 1056 & $6 \%$ & $\$ 527$ & $\$ 31$ \\
\hline 4 & $3+$ Increase Evap/Cond Coil Area & 10.7 & 193 & $16.2 \%$ & 998 & $36 \%$ & $\$ 674$ & $\$ 178$ \\
\hline 5 & $4+$ Incr Compressor EER to 11.3 & 11.1 & 224 & $18.8 \%$ & 966 & $46 \%$ & $\$ 723$ & $\$ 227$ \\
\hline 6 & $5+$ Incr Compressor EER to 11.4 & 11.2 & 232 & $19.5 \%$ & 958 & $50 \%$ & $\$ 746$ & $\$ 250$ \\
\hline 7 & $6+$ BPM Fan Motor & 11.5 & 259 & $21.7 \%$ & 932 & $74 \%$ & $\$ 865$ & $\$ 368$ \\
\hline 8 & $7+^{\star *}$ Variable Speed Compressor & 12.8 & 351 & $29.5 \%$ & 839 & $119 \%$ & $\$ 1,089$ & $\$ 592$ \\
\hline
\end{tabular}

Source: U.S. Dept. of Energy. Technical Support Document for Energy Conservation Standards for Room Air Conditioners. Sept. 1997.

Incremental costs to manufacturers to implement each design option are assumed to be the same in percentage terms in India as in the United States, and we expect these costs be passed on proportionally to the consumer. For example, an increase in efficiency from the 9.0 EER baseline to a level of 9.7 (design 1) is expected to add $4 \%$ to direct material and labor expenses to the manufacturer. Therefore, the retail price of this model is expected to be $4 \%$ higher than the current average of $\$ 497$, or $\$ 514$.

Split-system air conditioners are not considered separately for the engineering analysis. Savings and costs for these units are assumed to follow the same pattern as window air conditioners. Considering the small market share of these units, this creates only a small inaccuracy in evaluation of national impacts.

\section{Motors}

Electric motors represent a distinct case from refrigerators and air conditioners, for several reasons. In general, motors are relatively efficient products when they are run at design loads (80-90\%). High-efficiency motors reduce losses in both the windings (joule losses) and in the magnetic material of the core, most directly through the use of highquality materials. The reduction of annual energy consumption from these measures is generally of the order of a few percent, or equivalently, a reduction of losses on the order of $10-40 \%$. Such an efficiency improvement can be highly cost-effective due to the extensive operating hours in many agricultural or industrial applications. Operating hours are highly variable, however, producing a large degree of variability in energy savings. We consider two sectors for motor efficiency improvement: agricultural (irrigation pump) applications, and industrial (manufacturing) applications.

Incremental manufacturing costs for motors are generally a closely-held trade secret, and are thus difficult to obtain. Therefore we rely on retail price estimates provided by a recent study performed in a cooperation between International Institute for Energy 
Conservation and the International Copper Promotion Council India (IIEC 1999). Cost and energy consumption parameters are summarized in Table 4.

The prototype agricultural motor is a $3.8 \mathrm{~kW}$ (5 HP) unit typically used as part of an irrigation pump set. The efficiency improvement offered by a high efficiency motor of this capacity is $2 \%$. The improvement in efficiency from $83 \%$ to $85 \%$ leads to an increase of $15 \%$ in retail price, or an additional \$27. We assume that pumps are run 1700 hours per year at $75 \%$ of their rated capacity (Banerjee 1993).

We consider the example of industrial motors of $11 \mathrm{~kW}(15 \mathrm{HP})$ and $15 \mathrm{~kW}$ (20 HP) capacity as representative of the class of motors between $11 \mathrm{HP}$ and $50 \mathrm{HP}$, which represents roughly $10 \%$ of unit sales of low-tension squirrel cage (LTSC) motors (IIEC 1999) in India. While smaller motors dominate the market, these are less-likely to be used in high-intensity industrial applications, and actual use patterns are more difficult to estimate. Motors over $50 \mathrm{HP}$ hold a very small market share. Therefore, the 10-50 HP segment is the most likely to provide a relevant and accurate assessment of cost effectiveness.

The representative case of $11 \mathrm{~kW}$ and $15 \mathrm{~kW}$ show somewhat different levels of efficiency improvement. Efficiency improvement for a $11 \mathrm{~kW}(15 \mathrm{HP})$ motor is $2.2 \%$ (20\% reduction in losses), while for a $15 \mathrm{~kW}(20 \mathrm{HP}$ ) motor it is 4.5\% (39\% reduction in losses). Correspondingly, the percentage increase in price is higher for the larger motors ( $21 \%$ for $15 \mathrm{~kW}$ vs. $15 \%$ in the $11 \mathrm{~kW}$ case). Operating hour assumptions for industrial motors are considerably higher than in the agricultural case. Assuming that a typical industrial application has motors running 250 days per year for 2 eight-hour shifts per day, we arrive at an estimate of 4000 hours. We expect this is a typical load, but realize that there is a large amount of variability in operating hours, since some industrial facilities will operate for one shift per day, while others may be operating continuously (3 shifts).

The levels of efficiency assumed in this analysis are meant to represent those typically available in India rather than conform to a particular set of standards. It is useful, however, to compare these levels to common international practices. Therefore, we note that baseline efficiencies for India are all lower than the current minimum levels set by the U.S. Department of Energy, which are $89.5 \%, 90.2 \%$ and $90.2 \%$ for $3.8 \mathrm{~kW}, 11 \mathrm{~kW}$ and $15 \mathrm{~kW}$ respectively (USDOE 1999). The high efficiency case for agricultural motors still lies below the US minimum. For industrial motors, the high efficiency case exceeds the US minimum, and is equal or greater than the voluntary 'premium' level set by NEMA, which is $91 \%$ for both $11 \mathrm{~kW}$ and $15 \mathrm{~kW}$ motors. 
Table 4. Per Unit Efficiency Improvement and Incremental Manufacturer Cost for Motor Design Options

\begin{tabular}{|c|c|c|c|c|c|c|}
\hline \multicolumn{7}{|c|}{ AGRICULTURAL - $5 \mathrm{HP}$} \\
\hline \multirow{3}{*}{ Design } & \multicolumn{3}{|c|}{ Energy } & \multicolumn{3}{|c|}{ Equipment Price } \\
\hline & UEC & Losses & Loss Reduc. & $\%$ & \$US & \$US \\
\hline & kWh/year & kWh/year & $\%$ & Inc & Price & Inc \\
\hline $83 \%$ Efficiency & 5837 & 992 & 0 & 0 & $\$ 190$ & 0 \\
\hline 85\% Efficiency & 5720 & 875 & $12 \%$ & $15.0 \%$ & $\$ 219$ & $\$ 28.50$ \\
\hline \multicolumn{7}{|c|}{ INDUSTRIAL - $15 \mathrm{HP}$} \\
\hline \multirow{3}{*}{ Design } & \multicolumn{3}{|c|}{ Energy } & \multicolumn{3}{|c|}{ Equipment Price } \\
\hline & UEC & Losses & Loss Reduc. & Inc & Price & Inc \\
\hline & kWh/year & kWh/year & $\%$ & $\%$ & $\$$ SUS & $\$ U S$ \\
\hline 89\% Efficiency & 37079 & 4079 & 0 & 0 & $\$ 648$ & 0 \\
\hline $91 \%$ Efficiency & 36264 & 3264 & $20 \%$ & $15.1 \%$ & $\$ 746$ & $\$ 97.86$ \\
\hline \multicolumn{7}{|c|}{ INDUSTRIAL - $20 \mathrm{HP}$} \\
\hline \multirow{3}{*}{ Design } & \multicolumn{3}{|c|}{ Energy } & \multicolumn{3}{|c|}{ Equipment Price } \\
\hline & UEC & Losses & Loss Reduc. & Inc & Price & Inc \\
\hline & $\mathrm{kWh} /$ year & kWh/year & $\%$ & $\%$ & $\$$ US & \$US \\
\hline 89\% Efficiency & 50562 & 5562 & 0 & 0 & $\$ 561$ & 0 \\
\hline 93\% Efficiency & 48387 & 3387 & $39 \%$ & $21.0 \%$ & $\$ 678$ & $\$ 117.81$ \\
\hline
\end{tabular}

\section{Distribution transformers}

In general, efficiency improvement of distribution transformers in the Indian context is highly cost-effective. For this reason, and for simplicity, we consider only the "best technology' case, that is, transformer models that would receive the highest rating under the current rating scheme. We use the star rating as proposed by the Bureau of Energy Efficiency (BEE), India, based on survey data they collected in support of efficiency programs. The baseline is set at the current purchase practice conforming to the current standard (IS-1180). The losses for the baseline are set at 50\% load condition. Total power loss ratings for the BEE Star rating plan used in the analysis are given in Table 5.

Table 5 - Power loss ratings for BEE Star Plan

\begin{tabular}{|l|l|l|l|l|l|}
\hline \multirow{2}{*}{ Rating } & $25 \mathrm{kVA}$ & $63 \mathrm{kVA}$ & $\begin{array}{l}100 \\
\text { kVA }\end{array}$ & $160 \mathrm{kVA}$ & $\begin{array}{l}200 \\
\text { kVA }\end{array}$ \\
\cline { 2 - 6 } & \multicolumn{5}{|l|}{ Maximum Losses at 50\% Load in Watts } \\
\hline 1 Star & 290 & 490 & 700 & 1000 & 1130 \\
\hline 2 Star & 235 & 430 & 610 & 880 & 1010 \\
\hline 3 Star & 210 & 380 & 520 & 770 & 890 \\
\hline 4 Star & 185 & 330 & 440 & 670 & 780 \\
\hline 5 Star & 160 & 280 & 360 & 570 & 670 \\
\hline
\end{tabular}

Source: Indian Bureau of Energy Efficiency

The high efficiency level chosen for distribution transformers is well-understood in the Indian context, since we used levels already defined by BEE as voluntary rating levels. These levels can also be compared to levels defined by the National Electrical 
Manufacturers Association (NEMA) in the United States. NEMA's TP1 standards are defined as percentage efficiency at 50\% load, and assuming a power factor of 1.0. The levels are $98.7 \%, 98.6 \%, 98.8 \%, 98.9 \%$ and $99.0 \%$ for $25 \mathrm{kVA}, 63 \mathrm{kVA}, 100 \mathrm{kVA}, 160$ $\mathrm{kVA}$ and 200kVA respectively. The Indian 1 star level falls below this for all transformer sizes. Efficiency levels for 5 star transformers are 98.8\%, 99.2\%, 99.4\%, $99.3 \%$ and $99.4 \%$. These levels therefore exceed the TP1 standard by a significant margin.

There are two major components of energy loss incurred by distribution transformers: no-load losses, and load losses. The first of these occurs whenever the transformer is active, and is not significantly dependent on the transformer load. These losses are related to the transformer core. The other type of loss takes place in the coil, and is proportional to the square of the power passing through the unit at any given time. Load losses are calculated as the square of root-mean-square (RMS) loading adjusted for load growth.

Average energy consumed per unit capacity for affected stock therefore varies from year to year due to load growth effects. The annual unit energy consumption for distribution transformers for affected stock is given by

$$
U E C=E_{N L}+E_{L L} \times\left(L_{R M S}\right)^{2},
$$

where $E_{N L}$ and $E_{L L}$ are energy loss constants, $L_{R M S}$ is the root mean square of the load as a fraction of rated transformer capacity. The energy loss parameters $E_{N L}$ and $E_{L L}$ are given in turn by multiplying the power loss factors $P_{N L}$ and $P_{L L}$, respectively, by the number of hours in a year (8760) divided by 1000 , to yield $\mathrm{kWh}$.

Engineering data was provided by manufacturers in the form of energy loss ratings at $100 \%$ load. In order to estimate installed UEC, actual load levels must be taken into account. Transformer capacity is determined according to the maximum (peak) load they will carry, but on average, the load is much lower than the rated capacity. Table 6 gives engineering parameters and estimated equipment prices provided by manufacturers for baseline (1 Star) units and high-efficiency (5 Star) transformer models. Power loss ratings are given at $50 \%$ load in order to correspond to the BEE ratings. 
Table 6. Per Unit Efficiency Improvement and Incremental Manufacturer Cost for Distribution Transformers by Capacity Class

\begin{tabular}{|c|c|c|c|c|c|c|c|c|}
\hline \multicolumn{9}{|l|}{25 kVA } \\
\hline \multirow{3}{*}{ Rating } & \multicolumn{6}{|c|}{ Energy } & \multicolumn{2}{|c|}{ Equipment Price } \\
\hline & $P_{N L}$ & $P_{L L} @ 50 \%$ & $\mathrm{P}_{\text {тот }} @ 50 \%$ & $\mathrm{E}_{\mathrm{NL}}$ & $E_{\mathrm{LL}}$ & UEC & Price & $\Delta$ Price \\
\hline & Watts & Watts & Watts & kWh & kWh & $\mathrm{kWh}$ & \$US & \$US \\
\hline 1 Star & 86 & 166 & 252 & 753 & 284 & 1036 & $\$ 670$ & \\
\hline 5 Star & 27 & 122 & 148 & 232 & 208 & 441 & $\$ 1,007$ & $\$ 337$ \\
\hline \multicolumn{9}{|l|}{63 kVA } \\
\hline \multirow{3}{*}{ Rating } & \multicolumn{6}{|c|}{ Energy } & \multicolumn{2}{|c|}{ Equipment Price } \\
\hline & $\mathrm{P}_{\mathrm{NL}}$ & $P_{L L} @ 50 \%$ & $\mathrm{P}_{\text {тот }} @ 50 \%$ & $E_{N L}$ & $E_{L L}$ & UEC & Price & $\Delta$ Price \\
\hline & Watts & Watts & Watts & $\mathrm{kWh}$ & $\mathrm{kWh}$ & $\mathrm{kWh}$ & \$US & \$US \\
\hline 1 Star & 151 & 299 & 450 & 1323 & 511 & 1834 & $\$ 1,218$ & \\
\hline 5 Star & 50 & 210 & 260 & 438 & 359 & 797 & $\$ 1,678$ & $\$ 460$ \\
\hline \multicolumn{9}{|l|}{$100 \mathrm{kVA}$} \\
\hline \multirow{3}{*}{ Rating } & \multicolumn{6}{|c|}{ Energy } & \multicolumn{2}{|c|}{ Equipment Price } \\
\hline & $\mathrm{P}_{\mathrm{NL}}$ & $P_{L L} @ 50 \%$ & $\mathrm{P}_{\text {тот }} @ 50 \%$ & $\mathrm{E}_{\mathrm{NL}}$ & $E_{L L}$ & UEC & Price & $\Delta$ Price \\
\hline & Watts & Watts & Watts & $\mathrm{kWh}$ & $\mathrm{kWh}$ & $\mathrm{kWh}$ & \$US & \$US \\
\hline 1 Star & 216 & 427 & 643 & 1889 & 731 & 2619 & $\$ 1,446$ & \\
\hline 5 Star & 76 & 236 & 312 & 664 & 404 & 1068 & $\$ 1,951$ & $\$ 505$ \\
\hline \multicolumn{9}{|l|}{160 kVA } \\
\hline \multirow{3}{*}{ Rating } & \multicolumn{6}{|c|}{ Energy } & \multicolumn{2}{|c|}{ Equipment Price } \\
\hline & $\mathrm{P}_{\mathrm{NL}}$ & $P_{L L} @ 50 \%$ & $\mathrm{P}_{\text {тот }} @ 50 \%$ & $E_{N L}$ & $E_{L L}$ & UEC & Price & $\Delta$ Price \\
\hline & Watts & Watts & Watts & $\mathrm{kWh}$ & $\mathrm{kWh}$ & $\mathrm{kWh}$ & \$US & \$US \\
\hline 1 Star & 316 & 578 & 894 & 2768 & 989 & 3757 & $\$ 2,438$ & \\
\hline 5 Star & 103 & 439 & 542 & 902 & 751 & 1653 & $\$ 2,741$ & $\$ 303$ \\
\hline \multicolumn{9}{|l|}{$200 \mathrm{kVA}$} \\
\hline \multirow{3}{*}{ Rating } & \multicolumn{6}{|c|}{ Energy } & \multicolumn{2}{|c|}{ Equipment Price } \\
\hline & $\mathrm{P}_{\mathrm{NL}}$ & $P_{L L} @ 50 \%$ & Р $_{\text {тот }} @ 50 \%$ & $\mathrm{E}_{\mathrm{NL}}$ & $\mathrm{E}_{\mathrm{LL}}$ & UEC & Price & $\Delta$ Price \\
\hline & Watts & Watts & Watts & kWh & $\mathrm{kWh}$ & $\mathrm{kWh}$ & \$US & \$US \\
\hline 1 Star & 425 & 740 & 1165 & 3723 & 1266 & 4989 & $\$ 2,976$ & \\
\hline 5 Star & 113 & 519 & 632 & 991 & 888 & 1880 & $\$ 3,789$ & $\$ 813$ \\
\hline
\end{tabular}

Source: Determination Analysis of Standards and Labeling Program for Distribution Transformers, Indian Bureau of Energy Efficiency (BEE).

Total annual energy consumption is calculated from power losses assuming that the transformer is operating at all times. Therefore, for no-load losses, we simply multiply Watt losses by 8760 hours per year and divide by 1000 to arrive at kWh. For load losses, the consumption is given by

$$
E_{L L} x\left(L_{R M S}\right)^{2}
$$

Where $L_{R M S}$ is the average root mean squared load of each transformer, given by

$$
L_{R M S}=\sqrt{\sum_{t}(L(t) / \operatorname{Capacity}(t))^{2}}
$$


We estimate the current RMS loading of the system according to the current average load (in terms of percentage of rated transformer capacity) and the current load factor (average load divided by peak load). The current average load is calculated by dividing the total load of the system by the total installed transformer capacity. According to Central Electricity Authority, the country registered a total load of $65036 \mathrm{MW}$ in 2003 and recorded a total installed transformer capacity of 310496 MVA (CEA 2003-2004). This calculation yields an average load $L_{A V E}$ of $21 \%$ of capacity. The average load factor $L F$ defined as the ratio of average load to peak load, is 0.47 according to BEE. The relationship between average load, load factor and RMS load is strongly dependent on the variability in load over time. Unfortunately, load shape data for India are not readily available. Therefore, we rely on estimates of the relation between parameters estimated for the United States. According to (USDOE 2004), the relationship is given empirically by

$$
L_{R M S}=\left(1+1.4 \times \exp \left(-7^{*} L F\right)\right) * L_{A V E}
$$

This calculation results in an RMS loading of 0.22

Retail prices are estimated according to data provided by manufacturers to BEE. BEE asked the manufacturers to submit the loss and price data for the lowest cost transformer they could design for a set of specifications. The prices submitted through this process reflected the FORD, or the Free on Railway Destination price. This price is close to what can be considered the manufacturer's selling price as it includes sales tax, excise duty, shipping and packaging charges.

\section{Consumer Impacts Analysis}

To estimate the per-unit impacts of more efficient products on consumers, we used payback period, life-cycle cost (LCC) analysis, cost of conserved energy, and return on investment.

The payback period is the time required for savings in operating costs to equal the extra initial cost of a more efficient product.

The LCC is given by the following formula:

$$
L C C=P+\sum_{n=1}^{L} \frac{O C}{(1+D R)^{n}}
$$

where $P$ is the equipment retail price, $O C$ is the annual operating cost (electricity bill), and $D R$ is the consumer discount rate. The sum ranges over the lifetime of the appliance. The denominator in the sum accounts for the fact that future operating cost savings are valued less by the consumer ("discounted") than immediate first costs. 
We calculated the LCC for each design option considered for each product using the data from the technology cost-efficiency analysis, and discount rates for each sector. We interpret the design option with the lowest LCC to be the most cost efficient, and therefore an appropriate target for government efficiency programs, pending evaluation of other impacts.

Another indicator of cost-effectiveness is the Cost of Conserved Energy (CCE). Cost of conserved energy is the annualized increase in equipment costs divided by the value of annual energy saved through efficiency. These costs can be compared to the marginal price of electricity in order to assess the benefit to the consumer.

Finally, we also present the return on investment (ROI), which is the discount rate at which operating cost savings from the efficiency 'investment' equal the incremental first cost.

\section{Marginal Electricity Prices}

The consumer impacts analysis uses marginal energy prices to calculate the reduction in consumer energy costs associated with higher efficiency. Marginal energy prices are the prices paid for the last unit of energy used in a given billing period. Since marginal prices reflect a change in a consumer's bill associated with a change in energy consumed, such prices are appropriate for determining energy cost savings associated with efficiency.

For the LCC analysis we use estimated current marginal electricity prices. In all likelihood, the marginal prices in the 2010-2020 period will be higher than current prices, especially for residential and agricultural sectors. Thus, the use of current prices is a conservative assumption, since higher electricity prices will yield larger energy bill savings.

There is considerable sectoral cross-subsidization in the sale of electricity in India, with large industrial and commercial consumers paying the highest rates, and residential and especially agricultural consumers paying below the cost of production. There is, however, a block structure by which the marginal cost increases with consumption. This is generally true for all sectors but agriculture, where marginal cost increases are low or nonexistent in most states.

To estimate the current residential and commercial marginal electricity price, we obtained and analyzed the prevalent tariff structures. Most Indian residential and commercial consumers purchase electricity from State Electricity Boards (SEBs), so we based our estimates on their published tariffs. Table A-1 shows the rates at a usage of 100 $\mathrm{kWh} / \mathrm{month}$ for each state for which data was available (a household with a refrigerator would likely be in the $100 \mathrm{kWh} /$ month range). ${ }^{5}$ We arrived at a national average rate of

\footnotetext{
${ }^{5}$ We chose a household consumption level of $100 \mathrm{kWh} /$ month as provided by a study in Karnataka state by Murthy et al. (2001). More representative national household consumption data were not available. With the current tariff structures, we find that marginal rates would vary by less than $10 \%$ for household consumption within the $50 \mathrm{kWh} /$ month to $200 \mathrm{kWh} /$ month range.
} 
5.9 cents per $\mathrm{kWh}$ by weighting each state's rate by its urban population (those households likely to have refrigerators). Average marginal commercial rates were obtained using the same methodology, and by assuming a nominal monthly consumption of $500 \mathrm{kWh}$ for commercial enterprises. We arrived at a national average rate of 10.7 cents per kWh by weighting each state's rate by total commercial electricity consumption.

The price of electricity for agricultural consumers is currently 3.2 cents per $\mathrm{kWh}$. This low price is only a fraction of the estimated cost of electricity production, and is highly subsidized, partially via higher rates for customers in other sectors. We assume that by 2010 prices will will increase to 3.8 cents per $\mathrm{kWh}$ in accord with government policy on tariff reform, which requires that tariffs cover at least half of the cost of production. More detail on this assumption is given in the section on benefits to consumers below.

Industrial rates are currently close to the cost of production, and marginal rates are similar to average rates. We estimate the price of electricity to industrial customers to be 7.6 cents per $\mathrm{kWh}$.

For distribution transformers, the cost to utilities of energy losses in distribution transformers is calculated according to estimates of the per unit energy cost, rather than in terms of retail electricity price. We use the Availability Based Tariff (ABT) to represent the marginal cost of electricity supply or generation (see discussion below).

\section{Consumer Discount Rates}

Consumers value immediate savings more than future savings. The time value of money is typically accounted for by discounting future savings using a discount rate.

There is limited data on which to base consumer discount rates in India. The rate currently used by utilities for their investment in demand-side efficiency programs is $10 \%$. We assume that rates used for other sectors will be somewhat higher, with residential consumers discounting deferred savings by the largest factor. The sector discount rates are $15 \%$ for residential consumers. The rates used for other sectors are as follows: commercial $-12 \%$, industry $-12 \%$, agriculture $-15 \%$, utilities $--10 \%$.

\section{Life-Cycle Costs}

Refrigerators. Given a unit energy consumption (UEC) of $359 \mathrm{kWh}$ per year and a 2010 price of 5.9 cents per $\mathrm{kWh}$, the annual operation of a baseline direct cool refrigerator (design 0) would cost about \$21. As shown in Table 7, each subsequent combination of design options results in a lower UEC, with an accompanying increase in retail price.

For all of the design option combinations, payback to the consumer is less than three years, and all of them lower the LCC. Design option 3, which incorporates a reduction of 
heat leakage through the gasket, a more efficient compressor, and moderate insulation in the walls and door of the cabinet, has the lowest LCC. We estimate a discounted net savings of about $\$ 38$ over the life of the appliance for this unit. For the design options analyzed, CCE ranges from 1.5 to 3.0 cents per $\mathrm{kWh}$, well below the relevant electricity price. Return on investment to the consumer ranges between $33 \%$ and $68 \%$, consistent with payback periods of just a few years. Based on the LCC analysis, we chose design option 3 as the policy target in calculating national impacts.

Table 7. Consumer Financial Indicators for Direct-Cool Refrigerators

\begin{tabular}{|c|c|c|c|c|c|c|c|c|c|}
\hline \multirow{3}{*}{$\begin{array}{l}\text { Design } \\
\text { Number }\end{array}$} & \multirow[t]{2}{*}{ UEC } & \multirow{2}{*}{$\begin{array}{l}\text { Retail } \\
\text { Price }\end{array}$} & \multicolumn{2}{|c|}{$\begin{array}{c}\text { Annual Electricity } \\
\text { Bill } \\
\end{array}$} & \multirow[t]{2}{*}{$\begin{array}{l}\text { Payback } \\
\text { Period }\end{array}$} & \multicolumn{2}{|c|}{ Life-Cycle Cost } & \multirow{2}{*}{$\begin{array}{c}\text { Cost of } \\
\text { Conserved } \\
\text { Energy }\end{array}$} & \multirow{2}{*}{$\begin{array}{l}\text { Return on } \\
\text { Investment }\end{array}$} \\
\hline & & & Total & Change & & Total & Change & & \\
\hline & $\mathrm{KWh} / \mathrm{yr}$ & \$US & \multicolumn{2}{|c|}{ \$US } & Years & \multicolumn{2}{|c|}{ \$US } & $\$ U S / k W h$ & Per Annum \\
\hline 0 & 359 & $\$ 184$ & $\$ 21.31$ & $\$ 0.00$ & 0.00 & $\$ 308$ & $\$ 0.00$ & $\$ 0.000$ & \\
\hline 1 & 341 & $\$ 186$ & $\$ 20.24$ & $-\$ 1.07$ & 2.24 & $\$ 305$ & $-\$ 3.84$ & $\$ 0.023$ & $44 \%$ \\
\hline 2 & 276 & $\$ 191$ & $\$ 16.39$ & $-\$ 4.91$ & 1.46 & $\$ 287$ & $-\$ 21.54$ & $\$ 0.015$ & $68 \%$ \\
\hline 3 & 196 & $\$ 203$ & $\$ 11.64$ & $-\$ 9.67$ & 1.96 & $\$ 271$ & $-\$ 37.58$ & $\$ 0.020$ & $51 \%$ \\
\hline 4 & 190 & $\$ 207$ & $\$ 11.29$ & $-\$ 10.01$ & 2.33 & $\$ 273$ & $-\$ 35.20$ & $\$ 0.024$ & $43 \%$ \\
\hline 5 & 179 & $\$ 216$ & $\$ 10.61$ & $-\$ 10.69$ & 2.99 & $\$ 278$ & $-\$ 30.52$ & $\$ 0.030$ & $33 \%$ \\
\hline
\end{tabular}

Assumed lifetime: 15 years $^{6}$

Comparison of refrigerator efficiency levels with international practices is difficult, due to differences in product design, climate, use patterns and test procedures. Nevertheless, some indication of the efficiency of baseline and high-efficiency Indian refrigerators can be inferred by comparison to EU refrigerator standards passed in 1999. For the product class containing no freezer compartment, EU regulations require an annual energy consumption of no more than $252 \mathrm{kWh}$ for a 165 liter appliance (European Commission 2000). The baseline UEC in India of $359 \mathrm{kWh}$ is well above this level, and in fact corresponds roughly to the estimated baseline of European refrigerators before standards took effect there. The EU standard falls between design numbers 2 and 3 in our analysis. Design 3 uses 22\% less energy than the EU standard, and would therefore correspond to an ' $\mathrm{F}$ ' rating, where ratings run from $A$ to $G, A$ being the best and $G$ barely passing the minimum.

For frost-free units, we assume that incremental equipment costs and energy savings will scale with the direct-cool analysis. The estimated discounted savings for design option 3 is about $\$ 106$ over the life of the appliance (Table 8). For the design options analyzed, CCE ranges from 1.0 to 2.1 cents per $\mathrm{kWh}$. Return on investment to the consumer ranges between $48 \%$ to $99 \%$, consistent with payback periods of a year or so.

\footnotetext{
${ }^{6}$ Estimate by Tata Energy Research Institute, Delhi http://www.teri.res.in/teriin/news/terivsn/issue3/newsbrk.htm. Last Accessed Jan 10, 2005.
} 
Table 8. Consumer Financial Indicators for Frost-Free Refrigerators

\begin{tabular}{|c|c|c|c|c|c|c|c|c|c|}
\hline \multirow{3}{*}{$\begin{array}{l}\text { Design } \\
\text { Number }\end{array}$} & \multirow{2}{*}{ UEC } & \multirow{2}{*}{$\begin{array}{l}\text { Retail } \\
\text { Price }\end{array}$} & \multicolumn{2}{|c|}{ Bill } & \multirow{2}{*}{$\begin{array}{c}\text { Payback } \\
\text { Period }\end{array}$} & \multicolumn{2}{|c|}{ Life-Cycle Cost } & \multirow{2}{*}{$\begin{array}{c}\text { Cost of } \\
\text { Cons. Energy }\end{array}$} & \multirow{2}{*}{$\begin{array}{l}\text { Return on } \\
\text { Investment }\end{array}$} \\
\hline & & & Total & Delta & & Total & Delta & & \\
\hline & $\mathrm{KWh}$ & \$US & \multicolumn{2}{|c|}{ \$US } & Years & \multicolumn{2}{|c|}{ \$US } & \$US/kWh & Per Annum \\
\hline 0 & 876 & $\$ 311$ & $\$ 51.94$ & $\$ 0.00$ & 0.00 & $\$ 615$ & $\$ 0.00$ & $\$ 0.000$ & \\
\hline 1 & 832 & $\$ 315$ & $\$ 49.35$ & $-\$ 2.60$ & 1.56 & $\$ 603$ & $-\$ 11.15$ & $\$ 0.016$ & $64 \%$ \\
\hline 2 & 674 & $\$ 323$ & $\$ 39.97$ & $-\$ 11.97$ & 1.01 & $\$ 557$ & $-\$ 57.89$ & $\$ 0.010$ & $99 \%$ \\
\hline 3 & 479 & $\$ 343$ & $\$ 28.38$ & $-\$ 23.56$ & 1.36 & $\$ 509$ & $-\$ 105.78$ & $\$ 0.014$ & $74 \%$ \\
\hline 4 & 464 & $\$ 350$ & $\$ 27.53$ & $-\$ 24.42$ & 1.62 & $\$ 511$ & $-\$ 103.29$ & $\$ 0.016$ & $62 \%$ \\
\hline 5 & 436 & $\$ 365$ & $\$ 25.88$ & $-\$ 26.07$ & 2.07 & $\$ 516$ & $-\$ 98.35$ & $\$ 0.021$ & $48 \%$ \\
\hline
\end{tabular}

Assumed lifetime: 15 years

Air conditioners. Traditionally, most air conditioner sales in India have been to commercial customers, but rapid economic growth and the rise of a burgeoning middle class is a large driver of new sales. We therefore assume that in 2010, half of sales will be to residential consumers. Therefore, the relevant marginal energy price for air conditioners is taken to be the simple average of the residential marginal rate (estimated at 5.9 cents $/ \mathrm{kWh}$ in 2010 ) and the commercial marginal rate (estimated at 10.6 cents $/ \mathrm{kWh}$ in 2010)

Given a unit energy consumption (UEC) of $1063 \mathrm{kWh}$ per year and a marginal price of 8.3 cents $/ \mathrm{kWh}$, the annual operation of a baseline room AC (design 0 ) is estimated to cost about $\$ 99$.

For the first three design option combinations, payback to the consumer is less than three years (Table 9). In order to reach an EER level above 10.2, however, the incremental retail price increases dramatically. For this reason, the LCC is lower than the baseline only for the first 3 levels. Design option 3, which achieves 10.2 EER, has the lowest LCC. In calculating LCC for air conditioners, we use a discount rate of $13.5 \%$, which is the average of the residential discount rate of $15 \%$, and the commercial discount rate of $12 \%$. We estimate a discounted net savings of about $\$ 35$ over the life of the appliance for this unit. For this design option, the CCE is 3.9 cents per $\mathrm{kWh}$, well below the relevant electricity price. Return on investment to the consumer for this level is $36 \%$, consistent with a payback period of 2.8 years. Based on the LCC analysis, we chose the 10.2 EER design option as the policy target in calculating national impacts. For comparison, the US Department of energy required a minimum efficiency of 8.8 EER for this product class in its 1990 rulemaking. Standards effective in 2000 raised this minimum efficiency level to 9.7 (USDOE 1997a). 
Table 9. Consumer Financial Indicators for Room Air Conditioners

\begin{tabular}{|c|c|c|c|c|c|c|c|c|c|c|}
\hline \multirow{3}{*}{$\begin{array}{l}\text { Design } \\
\text { Number }\end{array}$} & \multirow{3}{*}{ EER } & \multirow{2}{*}{ UEC } & \multirow{2}{*}{$\begin{array}{l}\text { Retail } \\
\text { Price }\end{array}$} & \multicolumn{2}{|c|}{ Annual Electricity Bil } & \multirow{2}{*}{$\begin{array}{c}\text { Payback } \\
\text { Period }\end{array}$} & \multicolumn{2}{|c|}{ Life-Cycle Cost } & \multirow{2}{*}{\begin{tabular}{|c|} 
Cost of \\
Cons. Energy
\end{tabular}} & \multirow{2}{*}{$\begin{array}{l}\text { Return on } \\
\text { Investment }\end{array}$} \\
\hline & & & & Total & Change & & Total & Change & & \\
\hline & & KWh & \$US & \multicolumn{2}{|c|}{ \$US } & Years & \multicolumn{2}{|c|}{ \$US } & \$US/kWh & Per Annum \\
\hline 0 & 9.0 & 1191 & $\$ 497$ & $\$ 99$ & $\$ 0$ & - & $\$ 1,078$ & $\$ 0$ & $\$ 0.000$ & \\
\hline 1 & 9.7 & 1105 & $\$ 514$ & $\$ 92$ & $-\$ 7$ & 2.45 & $\$ 1,053$ & $-\$ 24$ & $\$ 0.034$ & $41 \%$ \\
\hline 2 & 10.0 & 1074 & $\$ 520$ & $\$ 89$ & $-\$ 10$ & 2.46 & $\$ 1,044$ & $-\$ 33$ & $\$ 0.035$ & $40 \%$ \\
\hline 3 & 10.2 & 1056 & $\$ 527$ & $\$ 88$ & $-\$ 11$ & 2.76 & $\$ 1,043$ & $-\$ 35$ & $\$ 0.039$ & $36 \%$ \\
\hline 4 & 10.7 & 998 & $\$ 674$ & $\$ 83$ & $-\$ 16$ & 11.11 & $\$ 1,161$ & $\$ 84$ & $\$ 0.157$ & $4 \%$ \\
\hline 5 & 11.1 & 966 & $\$ 723$ & $\$ 80$ & $-\$ 19$ & 12.20 & $\$ 1,195$ & $\$ 117$ & $\$ 0.172$ & $3 \%$ \\
\hline 6 & 11.2 & 958 & $\$ 746$ & $\$ 79$ & $-\$ 19$ & 12.97 & $\$ 1,214$ & $\$ 136$ & $\$ 0.183$ & $2 \%$ \\
\hline 7 & 11.5 & 932 & $\$ 865$ & $\$ 77$ & $-\$ 21$ & 17.16 & $\$ 1,320$ & $\$ 242$ & $\$ 0.242$ & $-2 \%$ \\
\hline 8 & 12.8 & 839 & $\$ 1,089$ & $\$ 70$ & $-\$ 29$ & 20.32 & $\$ 1,498$ & $\$ 421$ & $\$ 0.286$ & $-4 \%$ \\
\hline
\end{tabular}

Assumed lifetime: 12.5 years

Motors. As shown in Table 10, our analysis shows that efficiency measures for larger motors and motors used in industrial applications are highly cost-effective, especially for the larger motor. The CCEs are 2.5 cents per $\mathrm{kWh}$ for the $11 \mathrm{~kW}$ motor and 1.1 cents per $\mathrm{kWh}$ for the $15 \mathrm{~kW}$ motor. Both CCEs are much below the industrial electricity price.

The high-efficiency motor used in agricultural applications has an estimated CCE of 5.1 cents per $\mathrm{kWh}$, which is above the current price but below the cost of production of 7.7 cents per $\mathrm{kWh}$. Thus, the consumer cost-effectiveness for this application depends on reform of agricultural electricity prices.

Table 10. Consumer Financial Indicators for Motors

\begin{tabular}{|c|c|c|c|c|c|c|c|c|c|}
\hline \multicolumn{10}{|c|}{ AGRICULTURAL - $5 \mathrm{HP}$} \\
\hline \multirow{3}{*}{ Design } & \multirow[b]{2}{*}{ UEC } & \multirow{2}{*}{$\begin{array}{l}\text { Retail } \\
\text { Price }\end{array}$} & \multicolumn{2}{|c|}{ Annual Electricity Bill } & Payback & \multicolumn{2}{|c|}{ LCC } & \multirow{2}{*}{ CCE } & \multirow{2}{*}{\begin{tabular}{|l|} 
Return on \\
Investment
\end{tabular}} \\
\hline & & & Total & Delta & Period & Total & Delta & & \\
\hline & kWh/year & \$US & \$US & \$US & Years & \$US & \$US & $\$ / \mathrm{kWh}$ & Per Annum \\
\hline 83\% Efficiency & 5837 & $\$ 190$ & $\$ 224.82$ & $\$ 0.00$ & & $\$ 1,263$ & $\$ 0.00$ & & \\
\hline 85\% Efficiency & 5720 & $\$ 219$ & $\$ 220.30$ & $-\$ 4.51$ & 6.32 & $\$ 1,270$ & $\$ 6.97$ & $\$ 0.051$ & $8 \%$ \\
\hline \multicolumn{10}{|c|}{ INDUSTRIAL - $15 \mathrm{HP}$} \\
\hline \multirow{3}{*}{ Design } & \multirow[b]{2}{*}{ UEC } & \multirow{2}{*}{$\begin{array}{l}\text { Retail } \\
\text { Price }\end{array}$} & \multicolumn{2}{|c|}{ Annual Electricity Bill } & Payback & \multicolumn{2}{|c|}{ LCC } & \multirow{2}{*}{ CCE } & \multirow{2}{*}{\begin{tabular}{|c|} 
Return on \\
Investment
\end{tabular}} \\
\hline & & & Total & Delta & Period & Total & Delta & & \\
\hline & kWh/year & \$US & \$US & \$US & Years & \$US & \$US & $\$ / \mathrm{kWh}$ & Per Annum \\
\hline 89\% Efficiency & 37079 & $\$ 648$ & $\$ 2,824$ & $\$ 0.00$ & & $\$ 21,290$ & $\$ 0.00$ & & \\
\hline 91\% Efficiency & 36264 & $\$ 746$ & $\$ 2,762$ & -62.07 & 1.58 & $\$ 20,934$ & $-\$ 356$ & $\$ 0.025$ & $63 \%$ \\
\hline \multicolumn{10}{|c|}{ INDUSTRIAL - $20 \mathrm{HP}$} \\
\hline \multirow{3}{*}{ Design } & \multirow[b]{2}{*}{ UEC } & \multirow{2}{*}{$\begin{array}{l}\text { Retail } \\
\text { Price }\end{array}$} & \multicolumn{2}{|c|}{ Annual Electricity Bill } & Payback & \multicolumn{2}{|c|}{ LCC } & \multirow{2}{*}{ CCE } & \multirow{2}{*}{$\begin{array}{l}\text { Return on } \\
\text { Investment }\end{array}$} \\
\hline & & & Total & Delta & Period & Total & Delta & & \\
\hline & kWh/year & \$US & \$US & \$US & Years & \$US & $\$ U S$ & $\$ / \mathrm{kWh}$ & Per Annum \\
\hline 89\% Efficiency & 50562 & $\$ 561$ & $\$ 7,584$ & $\$ 0.00$ & & $\$ 28,708$ & $\$ 0.00$ & & \\
\hline 93\% Efficiency & 48387 & $\$ 678$ & $\$ 7,258$ & $-\$ 326.21$ & 0.71 & $\$ 27,616$ & $-\$ 1,093$ & $\$ 0.011$ & $277 \%$ \\
\hline
\end{tabular}

Assumed lifetime: 9 years for agricultural, 15 years for industrial

Distribution transformers. Estimates of financial benefits to electric utilities as a result of purchasing high efficiency transformers are calculated using the same methodology as for other equipment, with two important exceptions. First, as power delivery grows over time, each transformer is likely to experience some increase in load over its lifetime. Load growth occurs when new equipment, appliances, or additional activities occur on the circuits served by the distribution transformer. Load growth has the impact of 
increasing the load losses relative to the losses that we estimate during the first year of installation. The load is assumed to increase at a constant rate of $1 \%$ per year over the life of each transformer. For example, a transformer with initial load at $50 \%$ of capacity will face growth to about $55 \%$ load in 10 years, and roughly $60 \%$ load after 20 years. The unit energy consumption of the transformer in each year of its life is therefore given by

$$
U E C_{y}=E_{N L}+E_{L L} x(1.01)^{2 y}
$$

Second, the cost to utilities of energy losses in distribution transformers is calculated according to estimates of the per unit energy cost, rather than in terms of retail electricity price. We use the Availability Based Tariff (ABT) to represent the marginal cost of electricity supply or generation. ABT unbundles the availability charge from the energy charge. This availability charge is payable by all those State Electricity Boards who have either contracted for capacity creation with the generator or to whom capacity has been allocated. The availability charge comprises all fixed costs that have been prudently incurred by the generator as a consequence of installing capacity. Its recovery is linked to a target availability.

The average generation cost of 7.7 cents $/ \mathrm{kWh}$ is estimated based on historical data from the Planning Commission's Annual Report on State Electricity Boards and Electricity Departments.

The other component of $\mathrm{ABT}$ is Unscheduled Interchange (UI) charges. UI is the variation between actual generation or actual drawal and scheduled (allocated) generation or scheduled drawal. For a generating station, it is equal to its actual generation minus its scheduled generation. UI for a beneficiary is equal to its total actual drawal minus its total scheduled drawal. The UI charges as an add-on to the average generation cost can therefore be viewed as the price of generating an additional unit of electricity over the allocated quota. Table 11 provides the UI charge calculation for the country for the year 2003/04.

The table indicates that most of the power delivered by State Electricity Boards was at a frequency below 50.5 hertz, and therefore incurred UI charges. The UI charge can be viewed as a marginal cost that is currently paid on most energy delivered, but which provides an incentive for SEBs to reduce load, and therefore frequency distortion. The weighted-average UI charge for all regions is 4.9 cents per $\mathrm{kWh}$. Adding this to the average generation charge yields a total marginal cost of electricity of 12.6 cents $/ \mathrm{kWh}$. 
Table 11 - Unscheduled Interchange (UI)Charges by Region

\begin{tabular}{|c|c|c|c|c|c|}
\hline \multirow{2}{*}{\begin{tabular}{c} 
Frequency \\
\hline$>50.5 \mathrm{~Hz}$
\end{tabular}} & paise $/ \mathrm{kWh}$ & Northern & Western & Southern & $\begin{array}{c}\text { Eastern \& } \\
\text { N-Eastern }\end{array}$ \\
\hline $49-50.5 \mathrm{~Hz}$ & 215.3 & 5.8 & 2.4 & 0.4 & 1.1 \\
\hline$<49 \mathrm{~Hz}$ & 570 & 4.76 & 2.7 & 2.3 & 2.89 \\
\hline Electricity Generation & $\%$ & 28.1 & 32.9 & 27.3 & 11.8 \\
\hline Weighted UI & $\mathbf{2 2 0 . 8}$ & 219.7 & 219.7 & 222.5 & 223.2 \\
\hline cents/kWh & $\mathbf{4 . 9 1}$ & & & & \\
\hline
\end{tabular}

Source: Calculations based on frequency data from regional load dispatch centers.

As shown in Table 12, installation of high efficiency transformers provides a significant financial benefit to utilities. Even though increased incremental costs are large in percentage terms, the reduction in terms of losses is also large. Since transformers incur losses at all times they are in operation, the cumulative energy savings are substantial. As a result, payback period ranges from 4.5 years for the smallest capacity ratings to around 1 year for the $160 \mathrm{kVa}$ class. Cost of conserved energy ranges from 1 to 5.2 cents per kWh, well below the cost of electricity delivery. For the larger capacity transformers, which are the most common, the installation of high efficieny equipment could save the utility thousands of dollars per unit installed. 
Table 12. Consumer (Utility) Financial Indicators for Distribution Transformers

\begin{tabular}{|c|c|c|c|c|c|c|c|c|c|}
\hline \multicolumn{10}{|l|}{$25 \mathrm{kVA}$} \\
\hline \multirow{3}{*}{ Design } & \multirow{2}{*}{$\begin{array}{c}\text { First Year } \\
\text { UEC }\end{array}$} & \multirow{2}{*}{$\begin{array}{l}\text { Retail } \\
\text { Price } \\
\end{array}$} & \multicolumn{2}{|c|}{ Cost of Losses } & \multirow{2}{*}{\begin{tabular}{|l|} 
Payback \\
Period
\end{tabular}} & \multicolumn{2}{|c|}{ LCC } & \multirow{2}{*}{ CCE } & \multirow[b]{2}{*}{$\mathrm{ROI}$} \\
\hline & & & First Year & Average & & LCC & $\Delta \mathrm{LCC}$ & & \\
\hline & $k W h$ & \$US & \$US & \$US & Years & \$US & \$US & $\$ / \mathrm{kWh}$ & Per Annum \\
\hline $1 \mathrm{Star}$ & 1036 & $\$ 670$ & $\$ 131$ & $\$ 161$ & & $\$ 2,101$ & & & \\
\hline 5 Star & 441 & $\$ 1,007$ & $\$ 56$ & $\$ 68$ & 4.49 & $\$ 1,615$ & $-\$ 485$ & $\$ 0.052$ & $19 \%$ \\
\hline \multicolumn{10}{|l|}{$63 \mathrm{kVA}$} \\
\hline \multirow{3}{*}{ Design } & First Year & Retail & \multicolumn{2}{|c|}{ Cost of Losses } & Payback & \multicolumn{2}{|c|}{ LCC } & \multirow{2}{*}{ CCE } & \multirow[b]{2}{*}{$\mathrm{ROI}$} \\
\hline & UEC & Price & First Year & Average & Period & LCC & $\Delta \mathrm{LCC}$ & & \\
\hline & $\mathrm{kWh}$ & \$US & \$US & \$US & Years & \$US & \$US & $\$ / \mathrm{kWh}$ & Per Annum \\
\hline $1 \mathrm{Star}$ & 1834 & $\$ 1,218$ & $\$ 231$ & $\$ 284$ & & $\$ 3,750$ & & & \\
\hline 5 Star & 797 & $\$ 1,678$ & $\$ 101$ & $\$ 124$ & 3.51 & $\$ 2,779$ & $-\$ 971$ & $\$ 0.041$ & $26 \%$ \\
\hline \multicolumn{10}{|c|}{$100 \mathrm{kVA}$} \\
\hline \multirow{3}{*}{ Design } & First Year & Retail & \multicolumn{2}{|c|}{ Cost of Losses } & Payback & \multicolumn{2}{|c|}{ LCC } & \multirow{2}{*}{ CCE } & \multirow[b]{2}{*}{$\mathrm{ROI}$} \\
\hline & UEC & Price & First Year & Average & Period & LCC & $\Delta \mathrm{LCC}$ & & \\
\hline & $\mathrm{kWh}$ & \$US & \$US & \$US & Years & \$US & \$US & $\$ / k W h$ & Per Annum \\
\hline $1 \mathrm{Star}$ & 2619 & $\$ 1,446$ & $\$ 331$ & $\$ 406$ & & $\$ 5,062$ & & & \\
\hline 5 Star & 1068 & $\$ 1,951$ & $\$ 135$ & $\$ 166$ & 2.58 & $\$ 3,426$ & $-\$ 1,636$ & $\$ 0.030$ & $38 \%$ \\
\hline \multicolumn{10}{|c|}{160 kVA } \\
\hline \multirow{3}{*}{ Design } & First Year & Retail & \multicolumn{2}{|c|}{ Cost of Losses } & Payback & \multicolumn{2}{|c|}{ LCC } & \multirow{2}{*}{ CCE } & \multirow[b]{2}{*}{$\mathrm{ROI}$} \\
\hline & UEC & Price & First Year & Average & Period & LCC & $\Delta \mathrm{LCC}$ & & \\
\hline & kWh & \$US & \$US & \$US & Years & \$US & \$US & $\$ / \mathrm{kWh}$ & Per Annum \\
\hline $1 \mathrm{Star}$ & 3757 & $\$ 2,438$ & $\$ 474$ & $\$ 583$ & & $\$ 7,625$ & & & \\
\hline 5 Star & 1653 & $\$ 2,741$ & $\$ 209$ & $\$ 256$ & 1.14 & $\$ 5,024$ & $-\$ 2,601$ & $\$ 0.013$ & $89 \%$ \\
\hline \multicolumn{10}{|l|}{200 kVA } \\
\hline \multirow{3}{*}{ Design } & First Year & Retail & Cost of & Losses & Payback & & & CCE & \\
\hline & UEC & Price & First Year & Average & Period & LCC & $\Delta \mathrm{LCC}$ & CCE & $\mathrm{ROI}$ \\
\hline & kWh & \$US & \$US & \$US & Years & \$US & \$US & $\$ / k W h$ & Per Annum \\
\hline $1 \mathrm{Star}$ & 4989 & $\$ 2,976$ & $\$ 629$ & $\$ 774$ & & $\$ 9,863$ & & & \\
\hline 5 Star & 1880 & $\$ 3,789$ & $\$ 237$ & $\$ 291$ & 2.07 & $\$ 6,384$ & $-\$ 3,479$ & $\$ 0.024$ & $49 \%$ \\
\hline
\end{tabular}

Assumed lifetime: 22 years

\section{Forecast of Product Sales}

For each product, we developed a forecast of sales in each year in the 2010-20 period. The approach and data used are described in each section below.

\section{Refrigerators}

Currently, between 3 and 4 million refrigerators are sold in India each year. The great majority of these are produced in India by Indian firms, or by firms representing a joint venture with a North American or East Asian company. Foreign multinationals have traditionally had only a small presence in India, but now command a large share of the market. Direct imports from other countries are small. Furthermore, there is a strong trend towards consolidation, with the unorganized sector losing market to the bigger players and prices of units declining. 
Although the market does contain a component due to replacements of old refrigerators, growth is dominated by the entrance of households to the expanding middle class. As of 2002 , only $12 \%$ of households nationwide owned a refrigerator (Appliance Magazine), with very low levels of saturation in rural areas and among the poor, roughly half of whom do not have access to electricity.

Total sales of refrigerators in the years 1997-2002 was taken from a recent report (CLASP 2003). For 2003-2008, we relied on a forecast for sales provided by Euromonitor, a marketing research firm. These two sources combined indicate a ten-year average growth rate of $5.9 \%$ per year. We assume that this rate of total sales will continue throughout the forecast period. Our forecast shows sales growing from roughly 3.5 million units in 2002 to around 9 million in 2020 (Figure 1). A more precise forecast is inhibited by the large uncertainties in predicting the number of households that will be able to afford refrigerators.

The current market split is $82 \%$ direct-cool and $18 \%$ frost-free units. As mentioned previously, the frost-free sector continues to gain market share. We assume that it will gradually increase until it reaches $25 \%$ share by 2020 , perhaps a conservative assessment.

Figure 1 - Unit Refrigerator Sales, 2000-2020

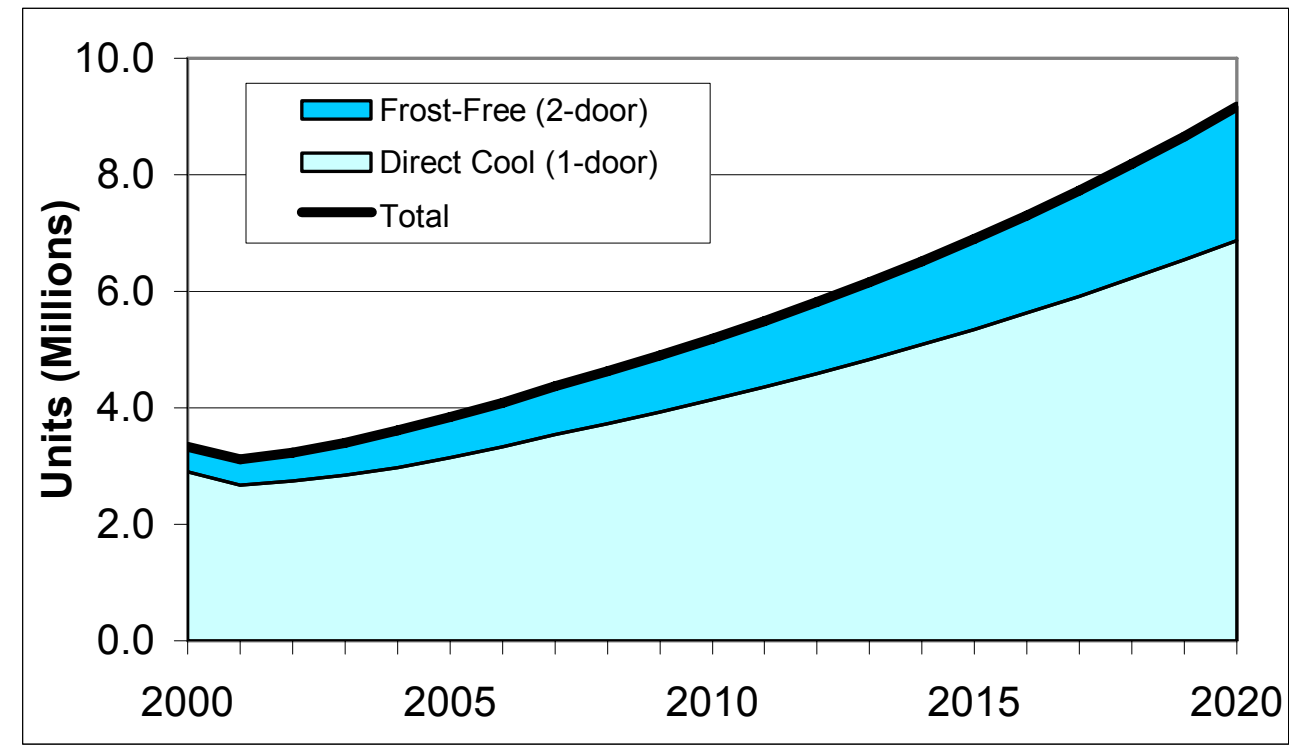

\section{Air conditioners}

The new and increasing residential customer base for air conditioners has caused dramatic growth in the industry in recent years at rates of more than $20 \%$ per annum. ${ }^{7}$ There is still great potential for growth in the residential sector, as household saturation rates are still around the $1 \%$ level. A further impetus for sales growth has been the lowering of value-added tariffs.

\footnotetext{
${ }^{7}$ Source: Euromonitor
} 
In line with a general trend towards manufacturing industry consolidation, the unorganized sector, which once was dominant in air conditioner manufacturing, has given way to large firms, including multinationals, which now control about $80 \%$ of the market. We forecast sales only for the organized sector, as we assume that it would be more difficult to implement efficiency measures in the unorganized sector. Sales in the organized sector totaled 660,000 units in 2002, a dramatic increase from only 264,000 in 1998 (a 17\% per annum growth rate). Growth in air conditioners is expected to be even larger during the 2002-2007 period, reaching 25\% per annum (Euromonitor 2003). We assume that the growth rates will level to $15 \%$ between 2008 and 2010, and remain constant at $10 \%$ throughout the period 2010-2020, as saturation effects become significant. We assume that the share of split-system air conditioners remains constant at $17 \%$ throughout the forecast period.

Figure 2 - Unit Room Air Conditioner Sales, 2000-2020

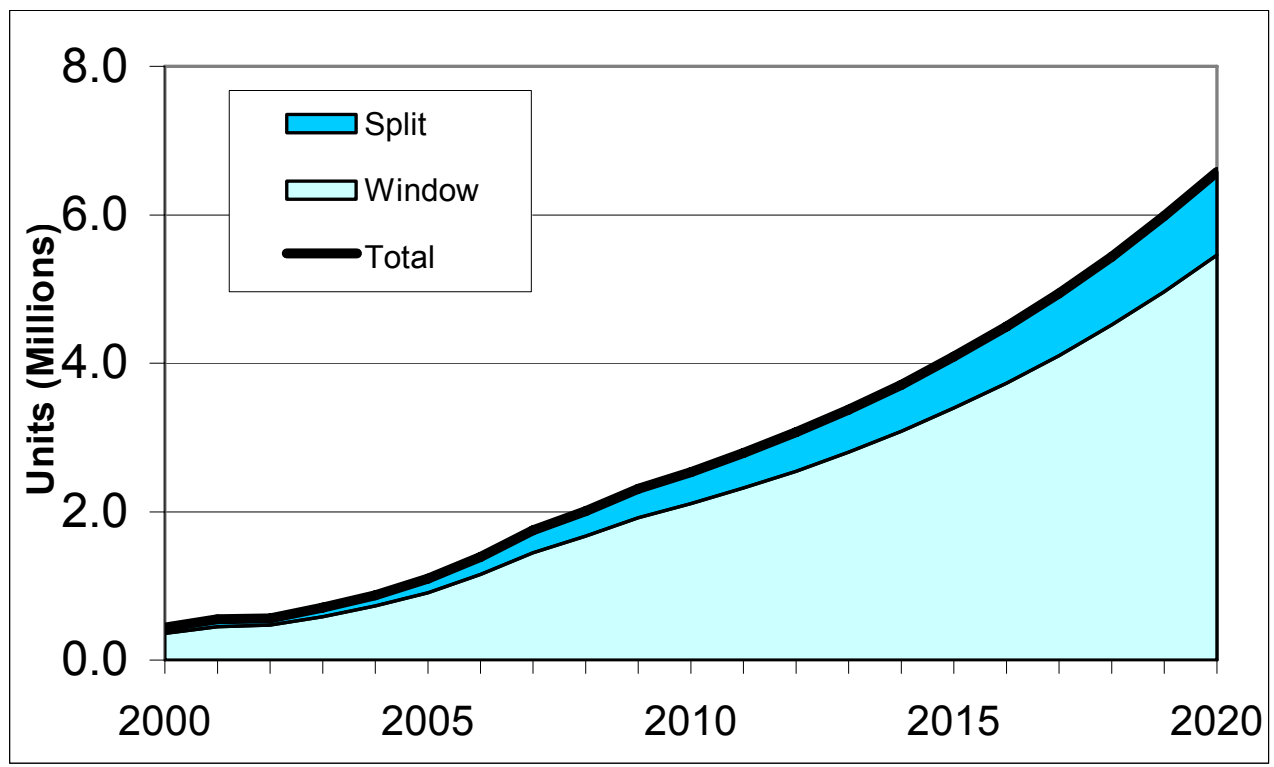

\section{Motors}

India possesses an enormous number of irrigation pump sets in its rural areas. Recent estimates indicate that, as of 2002, over 13 million pump sets were energized throughout India (Planning Commission 2002). The same report estimates the total potential for pump-sets at just under 20 million. Recent increase in the number of energized pump sets implies new sales of pump sets on the order of 400,000 to 500,000 per year, with a sales growth of about 3.3\% in recent years (1995-2001). At this rate, the total potential of 20 million will be approached around 2020. As the sector becomes saturated, energization growth rates are likely to slow, and the market will be replacementdominated. We forecast a smooth approach to market saturation, with energization rates continuing to grow at $1 \%$ per year until 2010 , but thereafter dropping off proportional to the remaining potential in each year. Throughout the forecast, replacements are expected 
to grow according to the retirement function applied to past shipments. We assume the same general retirement function shape as with refrigerators and air conditioners, but with a 9 year mean lifetime.

According to IEEMA production statistics, domestic production of low-tension squirrel cage (LTSC) motors in the organized sector grew from 467,000 in 1992 to 620,000 in 1997, with a high of 715,000 in the intervening years (1994) (IIEC 1999). In addition, there were a large number of imports. $90 \%$ of the LTSC motors are less than $10 \mathrm{HP}$ (a large fraction of which are accounted for by agricultural pump sets). The remaining 10\% are over $10 \mathrm{HP}$. Between 1998 and 2003, production of 10-50 HP motors is assumed to scale with IEEMA production indices in terms of total motor capacity (IEEMA 2003). After 2003, since motor use is such an integral contributor to industrial production, we assume that motor sales will increase with forecasts of growth in industrial production. These are 5.3\% in the period 2004-2010 and 5.7\% in the period 2010-2020 (Planning Commission 2002).

Figure 3 - Unit Motor Sales, 2000-2020

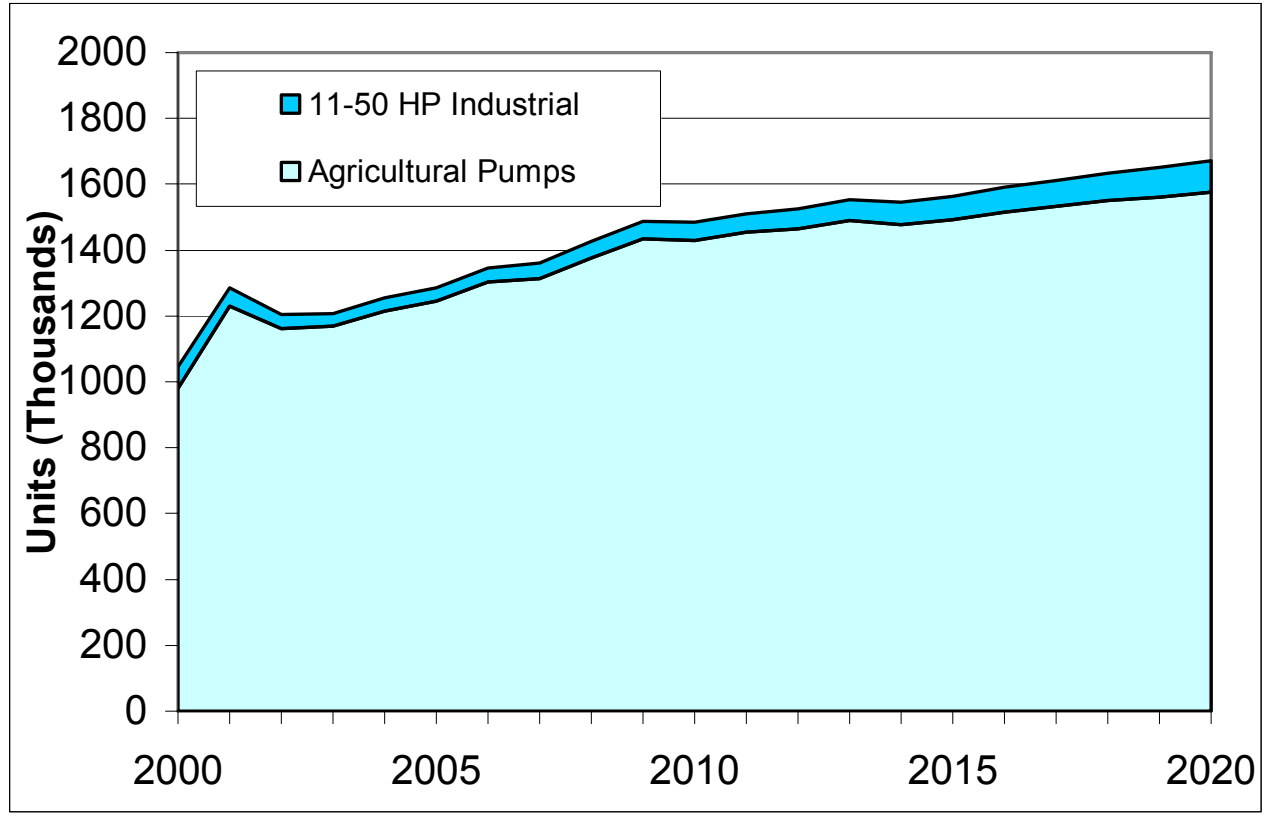

\section{Distribution transformers}

Distribution transformer sales are primarily driven by increases in the total generation capacity of the power system. Generation increased at an average rate of $6.7 \%$ from 1990-2000. According to energy sector researchers in India, high growth rates are expected to continue through the coming decades, with annual growth rates ranging between 5 and 7\% (Planning Commission 2004). 
Between 1970 and 1994, total transformer capacity in MVA is given by ASI Production indices $^{8}$, scaled to 1995 production values for transformers. From 1995 to 2002, manufacturer estimates (IEEMA 2003) are used. After 2002, the stock of transformers is expected to scale with generation capacity. Once the total transformer capacity shipments are determined, shipments of each capacity class are calculated according to estimated market shares of each class.

Figure 4 - Distribution Transformer Sales in MVA, 2000-2020

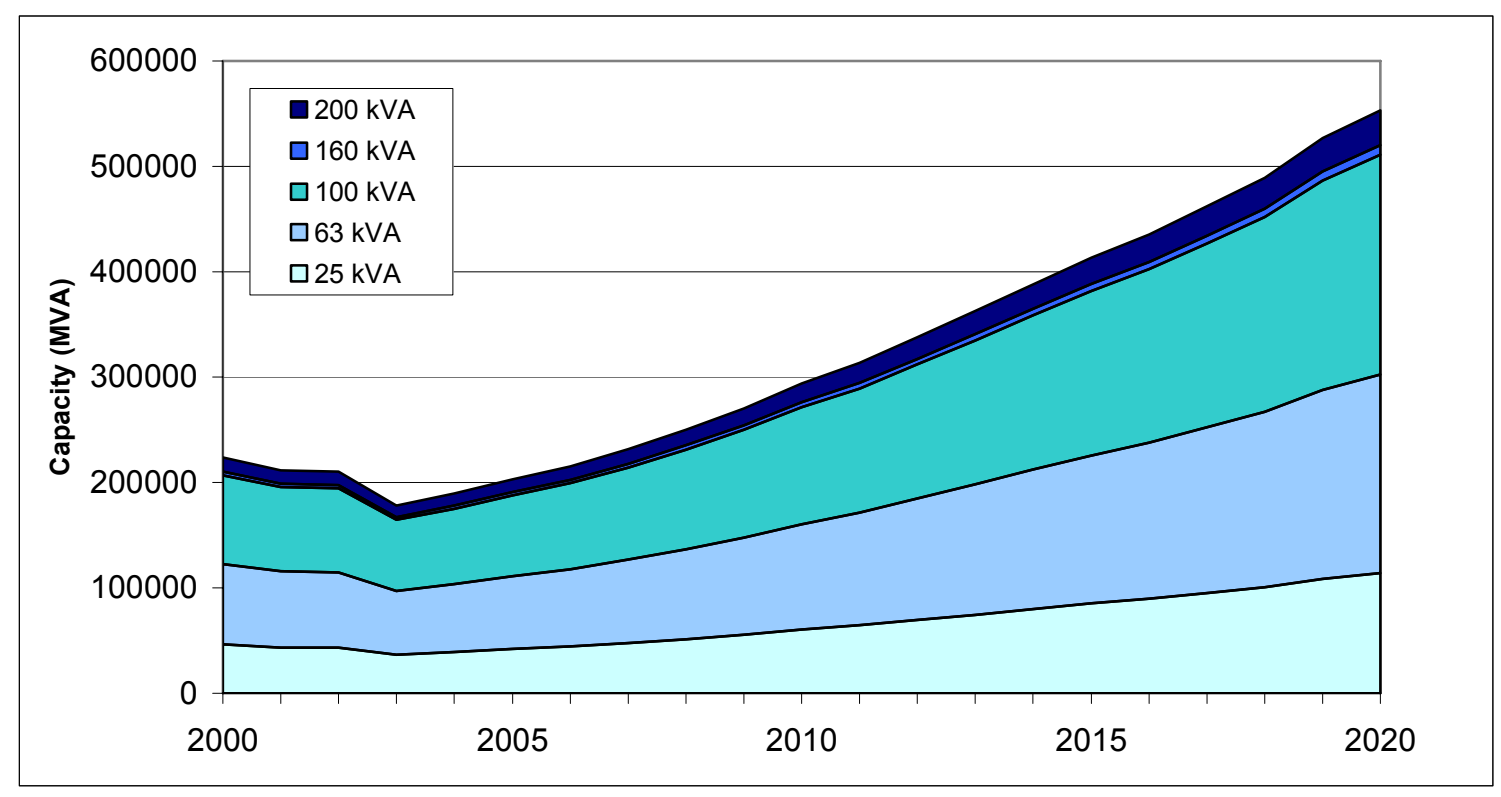

\section{National Impacts of the High Efficiency Case}

The Base Case provides a reference against which we measure the potential impacts of the High Efficiency Case. The Base Case employed assumes no improvements in the baseline efficiency, and no change in the (inflation adjusted) retail price of the baseline units.

The High Efficiency Case assumes that a mixture of market forces and policy initiatives result in a situation in which the average efficiency of products sold in 2010 and thereafter meets the efficiency of the design option that provides the minimum LCC. This assumption corresponds to achievement of the full cost-effective potential of efficiency improvement. A lack of data on historical trends in efficiency makes it difficult to assess to what extent efficiency of the considered products may improve in India due to market forces. However, we believe that less than a quarter of the benefits of the High Efficiency Case would be captured without policy initiatives.

\footnotetext{
${ }^{8}$ Index for Electrical Machinery Apparatus and Appliances
} 
All sales of products during the 2010-20 period are affected by the policy, and savings are estimated from these products only. Sales that occur after 2020 do not affect national savings; however, there are savings due to units that remain in the stock after this time. We calculate energy and cost savings until the last unit shipped in 2020 is retired from the stock.

\section{Stock Forecast}

The total stock and vintage of appliances in any given year is needed in order to calculate national energy consumption and savings. The stock is calculated using a straightforward accounting method that takes each year's sales as input. For each year, some fraction of the cohort installed in previous years remains, according to a survival function. For the purposes of this analysis, the survival function is a simple curve based on the average lifetime.

Figure 5 shows the survival function for refrigerators and air conditioners. According to this function none of the refrigerators are retired before 10 years $(2 / 3$ of the mean lifetime of 15 years), and all of them are replaced by 20 years (4/3 of the mean lifetime). Between these limits, the probability of retirement is a straight line. The survival function for air conditioners is of the same form, but uses a mean lifetime of 12.5 years, as estimated by the U.S. Department of Energy in its technical analysis of proposed standards (USDOE, 1997).

Figure 5 - Product Survival Functions

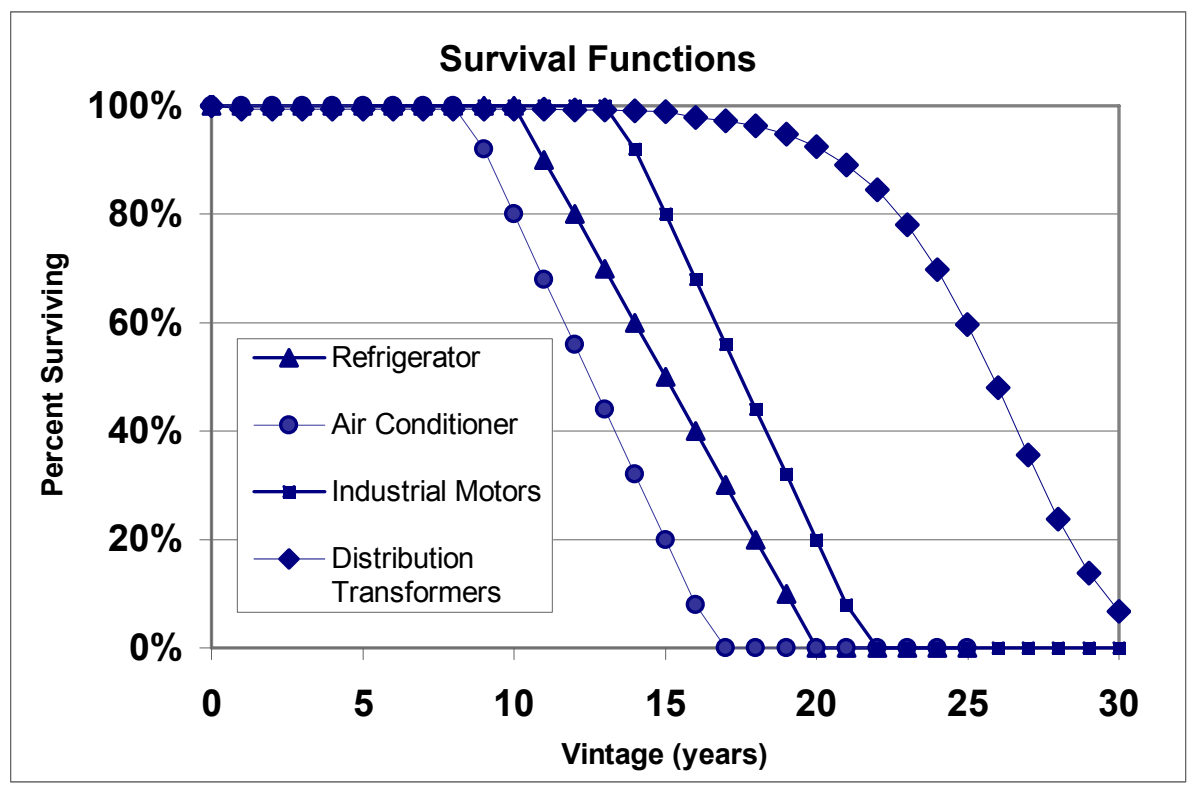

Stock and shipments of distribution transformers are related, as in the case of the other types of equipment covered in this report, through a retirement and replacement model, according to the mean lifetime of 22 years. The lifetime is given by a Weibull function of the form 


$$
\text { Survival }(\text { age })=e^{-(\text {age/a })^{b}} \times\left(1-F_{\text {Const }}\right)^{\text {age }} \times\left(1-F_{\text {Corrosion }}\right)^{\text {age-15 }}
$$

The constant failure rate, $F_{\text {Const }}$ is $0.65 \%$ per year. After the transformer is 15 years old, there is an additional corrosion failure rate $F_{\text {Corrosion }}$ of $0.65 \%$ per year (ORNL 1995). The parameters $a$ and $b$ were adjusted for the Indian case, so that the mean lifetime of the equipment corresponds to the value reported by the Indian Bureau of Energy Efficiency.

\section{Energy Consumption by Consumers}

Total annual energy consumption by consumers in the Base Case and the High Efficiency Case is calculated by multiplying the remaining stock from each cohort by the unit energy consumption (see Appendix 2 for equations).

We consider that some changes in average product size and/or features are likely between today and 2020. Such change will affect the UECs. For example, the market share of frost-free refrigerators is increasing. It is also likely, however, that frost-free refrigerators will become larger. We therefore apply a UEC growth rate of $1 \%$ for frost-free units over the forecast period. We assume that this rate of increase will be accomplished through improved manufacturing processes and economies of scale, and will therefore impose no price increase. No increase in average capacity over time is assumed for room air conditioners.

In calculating national energy impacts of a high efficiency policy for air conditioners, we take into account that roughly $5 \%$ of the models available on the retail website surveyed (www.compareindia.com) were above the target efficiency level of 10.2 EER. We assume that this percentage corresponds to the sales market share of efficient models, thus lowering the market-weighted base case UEC.

Table 13 gives the Base Case and Efficiency Case average UEC values by product in 2010. 
Table 13. Average Unit Energy Consumption Values in 2010

\begin{tabular}{|c|c|c|c|}
\hline Product & $\begin{array}{l}\text { Base Case } \\
\text { (kWh/year) }\end{array}$ & $\begin{array}{c}\text { Efficiency Case } \\
\text { (kWh/year) }\end{array}$ & $\begin{array}{c}\text { Percentage } \\
\text { Improvement }\end{array}$ \\
\hline \multicolumn{4}{|l|}{ Refrigerator } \\
\hline Direct-cool & 381 & 208 & $45 \%$ \\
\hline Frost-free & 930 & 508 & $45 \%$ \\
\hline \multicolumn{4}{|l|}{ Room air conditioner } \\
\hline Window $^{9}$ & 1191 & 1056 & $11 \%$ \\
\hline \multicolumn{4}{|l|}{ Motors } \\
\hline Agricultural - $5 \mathrm{HP}$ & $992^{10}$ & 875 & $12 \%$ \\
\hline Industrial - $15 \mathrm{HP}$ & 4079 & 3264 & $20 \%$ \\
\hline Industrial - $20 \mathrm{HP}$ & 5562 & 3387 & $39 \%$ \\
\hline \multicolumn{4}{|c|}{ Distribution transformer } \\
\hline $25 \mathrm{kVA}$ & 1036 & 441 & $57 \%$ \\
\hline $63 \mathrm{kVA}$ & 1834 & 797 & $57 \%$ \\
\hline $100 \mathrm{kVA}$ & 2619 & 1068 & $59 \%$ \\
\hline $160 \mathrm{kVA}$ & 3757 & 1653 & $56 \%$ \\
\hline $200 \mathrm{kVA}$ & 4989 & 1880 & $62 \%$ \\
\hline
\end{tabular}

Figure 6 shows the total electricity consumption by refrigerators over time in the Base Case and the High Efficiency Case. The sharp change in 2010 is a function of our method. In reality, there may be a ramp-up in the High Efficiency Case prior to 2010 as market forces and policies begin to have an impact. The significant opportunities for cost-effective efficiency improvement for this product are evident. The result of efficiency improvement is that growth of electricity consumption for this product is slowed to only a fraction of growth in the size of the stock.

\footnotetext{
${ }^{9}$ Consumption patterns and engineering parameters for window air conditioners assumed to hold for split systems for the purposes of this study.

${ }^{10}$ For comparison with other products, energy consumption and percentage improvement for motors is given in terms of losses, thus excluding the useful mechanical output energy produced by the motor.
} 
Figure 6 - Total Electricity Consumption by Refrigerators in India

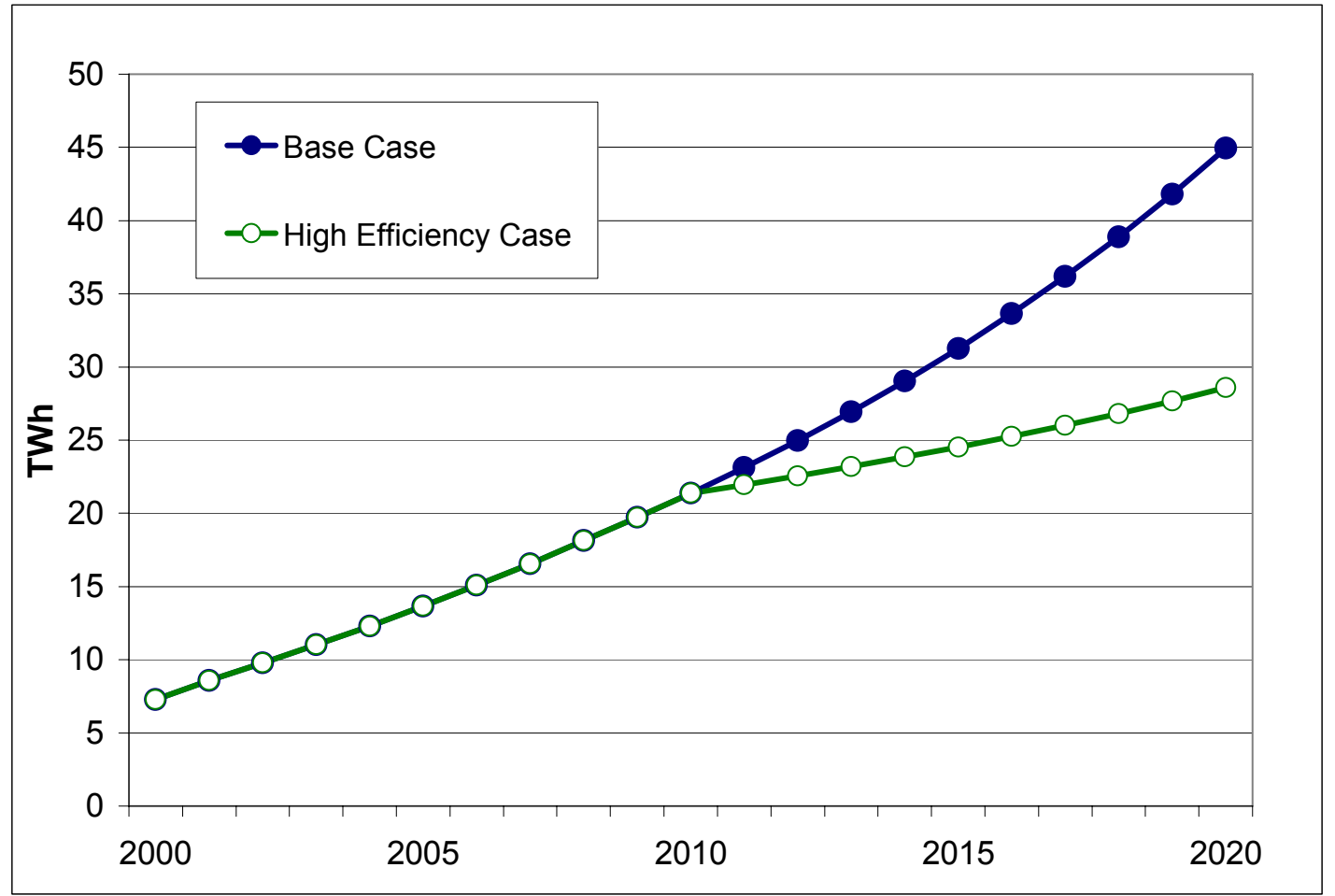

Figure 7 shows the total electricity consumption by room air conditioners over time in the Base Case and the High Efficiency Case. Because of constraints of cost-effectiveness, percentage efficiency improvement is much lower than in the refrigerator case. Nevertheless, energy savings for air conditioners is significant, due to the extraordinary growth in the use of this product in India. 
Figure 7 - Total Electricity Consumption by Air Conditioners in India

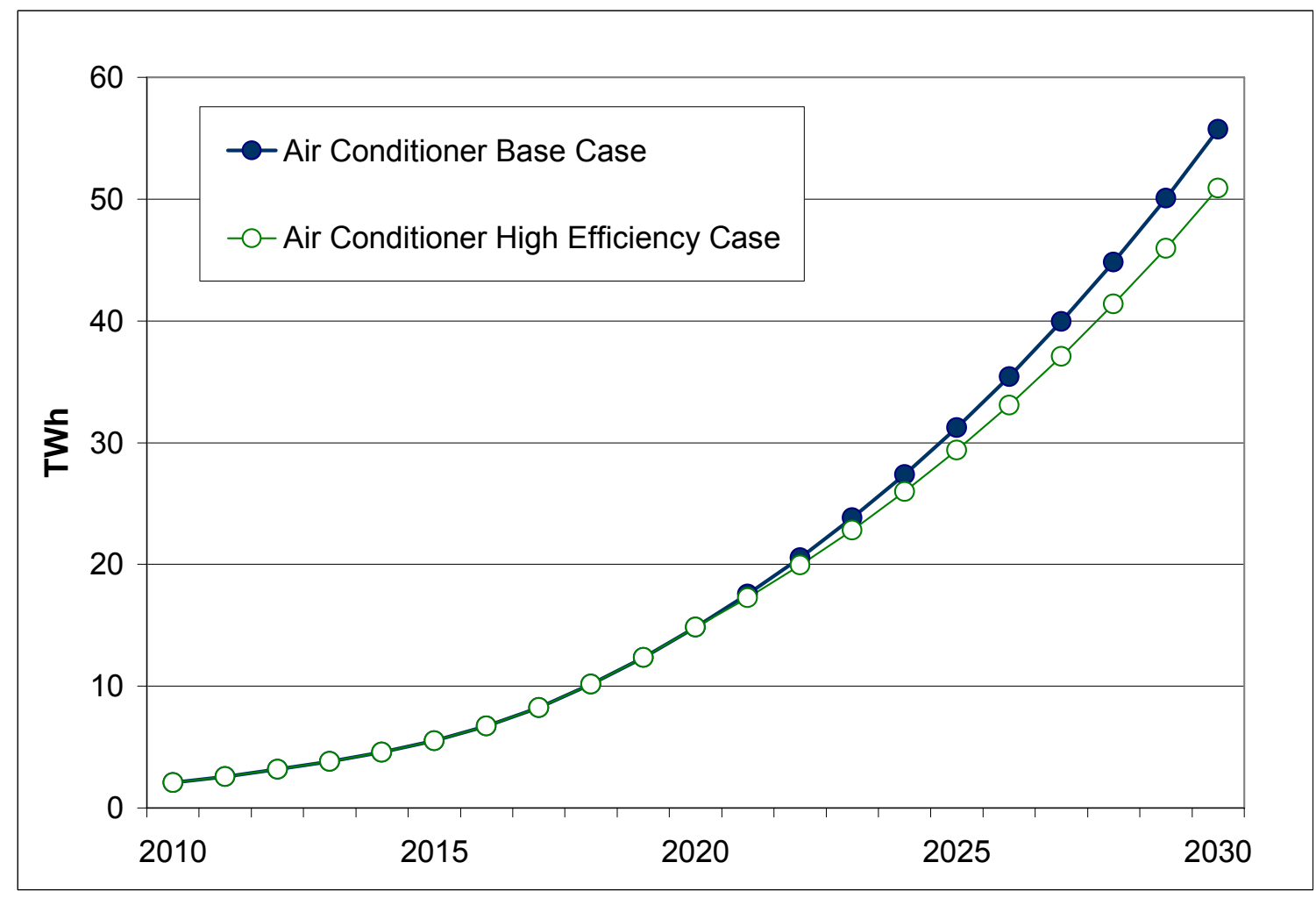

Figure 8 shows the total electricity consumption by motors over time in the Base Case and the High Efficiency Case. The percentage improvement in efficiency for motors is small compared to the other equipment types analyzed, since motors are already relatively efficient. In absolute terms, however, electricity savings from motors is comparable to the other products, since the baseline energy consumption is very high. 
Figure 8 - Total Electricity Consumption by Motors

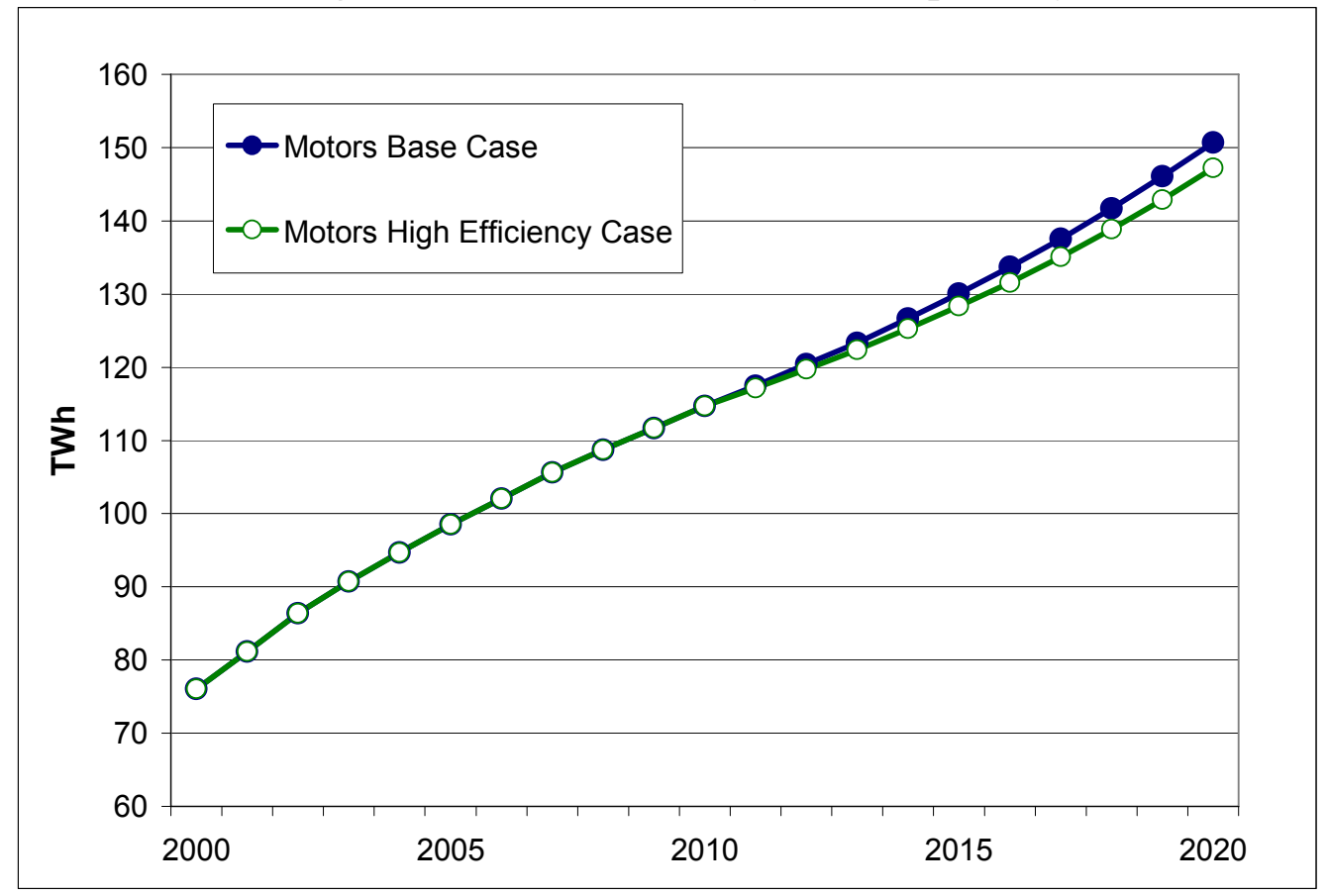

Figure 9 shows the total electricity consumption by distribution transformers over time in the Base Case and the High Efficiency Case. Total electricity consumption (losses) in transformers is equivalent to only a fraction of the other products studied. In this case, however, losses can be dramatically reduced through efficiency measures.

Figure 9 - Total Electricity Consumption by Distribution Transformers

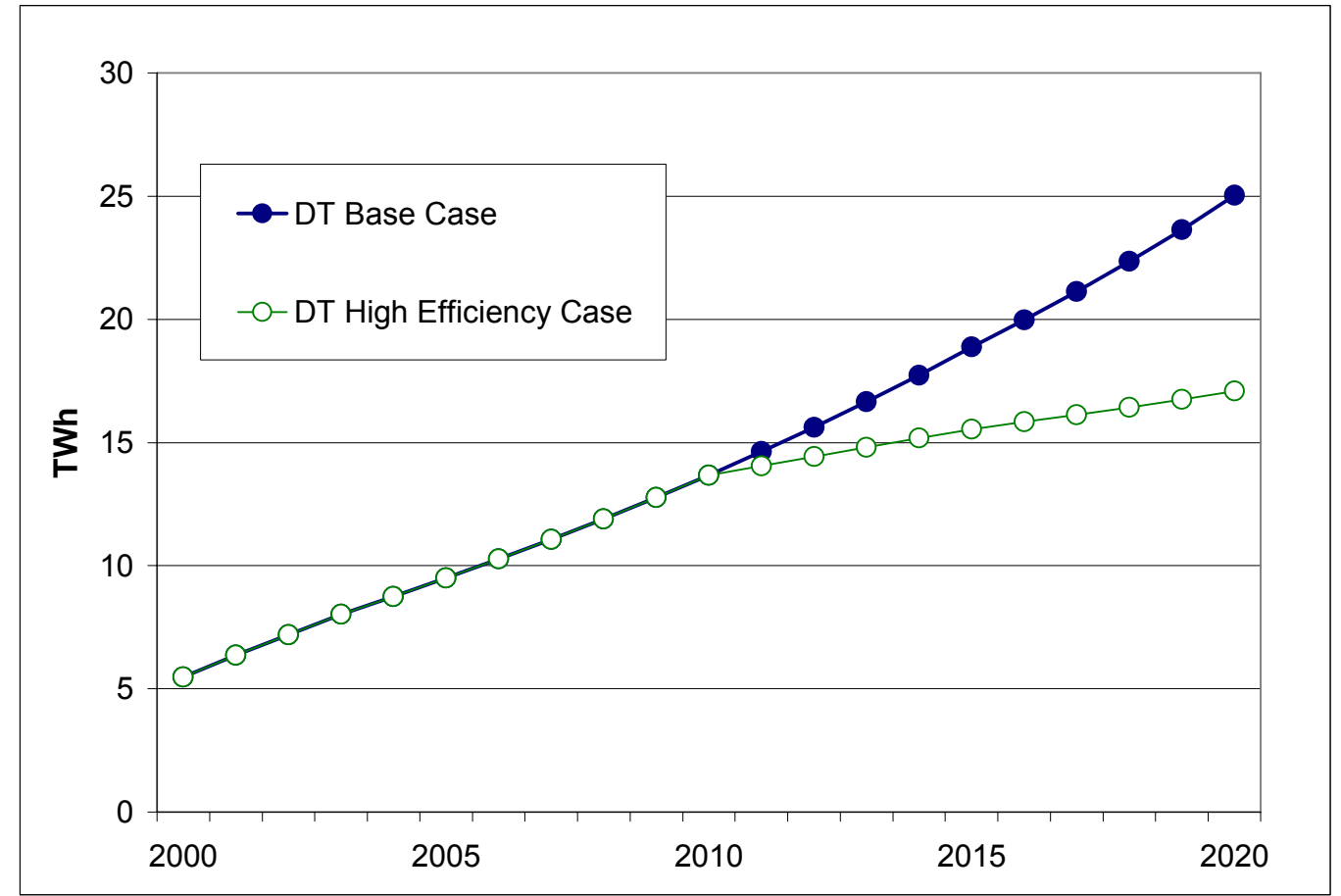




\section{Benefit to Consumers}

The Net Present Value (NPV) to consumers represents the net financial savings to consumers yielded by use of the High Efficiency Case products, discounted to the present year (2005). Financial impacts are calculated at the national level using the aforementioned shipments and stock forecasts (see Appendix 2).

It is difficult to obtain a reliable forecast for marginal electricity prices in the Indian context. Production costs may increase or decrease according to world fuel prices and the availability of domestic coal and hydropower. An even more significant consideration is the increasing pressure to reduce subsidies, and general fiscal reform (privatization) of the power sector. According to recent estimates, average electricity tariffs in India cover only 69\% of costs (Planning Commission 2002), which were estimated at 350 paise $/ \mathrm{kWh}$ (equal to $7.4 \mathrm{US}$ cents $/ \mathrm{kWh}$ measured in 2003 dollars). The report estimates that residential tariffs cover only $56 \%$ of the cost of production. ${ }^{11}$ The industrial and commercial sectors pay more than the cost of production (108\% and $122 \%$ respectively). Agriculture is the most highly subsidized sector, with average tariffs covering only $12 \%$ of the cost of production.

We estimated marginal rates to consumers for each sector according to current tariff structures. This analysis shows that while residential tariffs are highly subsidized, the residential tariff is highly dependent on consumption so that households pay a much higher price for the last unit of electricity consumed than the average over the entire utility bill. Therefore, the energy saved by purchasing efficient equipment will yield greater cost savings than average tariffs would indicate. We find an marginal cost in the residential sector of 5.9 cents per $\mathrm{kWh}$, which is $81 \%$ of the estimated cost of production. Commercial consumers also pay a premium for consumption, with a marginal rate of 10.6 cents per $\mathrm{kWh}$. The details of marginal rate calculation for these two sectors are given in Appendix 1.

For the industrial sector, although average costs are higher than those paid in the residential sector, there is little difference between average and marginal rates paid. The marginal rate is relatively constant over a wide range of consumption, and is found to be 7.6 cents per $\mathrm{kWh}$, which is quite close to the cost of production. Finally, average agricultural rates are quite low and there is very little increase in charges as a function of total consumption. The marginal agricultural tariff is only 3.2 cents per $\mathrm{kWh}$, and is quite insensitive to consumption.

We expect that between now and 2010, there will be continued efforts to bring residential and agricultural tariffs in line with the cost of electricity production. In particular, agricultural rates are a main focus of tariff reform in India, and have been raised significantly in several Indian states. The Common Minimum National Action Plan for Power issued in 1996 by the Chief Ministers of Indian States led by the Government of India decrees that "no sector...shall pay less than $50 \%$ of the average cost of supply" (IEA 2002). According to the most recent report on State Electricity Boards (Planning

${ }^{11}$ Revenues received by utilities amount to less than this value, since there is a fair amount of electricity theft or non-collection of bills. 
Commission 2002), the average cost of production was 7.7 cents per $\mathrm{kWh}$. We therefore make the relatively conservative assumption that agricultural marginal tariffs will increase from the current value of 3.2 cents to 3.8 cents per $\mathrm{kWh}^{12}$. The residential sector will also be a likely target of tariff reform. Since the degree to which subsidies will be reduced is difficult to predict, however, we assume that current marginal rates will prevail throughout the forecast period.

The net savings in each year arises from the difference in incremental equipment and operating costs in the High Efficiency Case versus the Base Case. Net Present Value of the High Efficiency Case is then defined as the sum over the forecast period of the net national savings in each year, multiplied by the appropriate national discount rate. We use a national discount rate of $10 \%$, the rate currently used by the World Bank for projects in India.

As an example of the time trend of impacts, consumer financial impacts for refrigerators in the High Efficiency Case are shown in Figure 8. From 2010 to 2020, incremental equipment costs and operating cost savings are steadily increasing as equipment is purchased and enters the stock under the high-efficiency policy regime. Operating cost savings grow more rapidly, since they are cumulative - refrigerators purchased in 2010 are still in the stock producing savings, while those purchased in 2011 also begin to provide savings. Savings peak in 2020 and thereafter decline, while incremental costs stop. This is because we do not count impacts for sales after 2020. After 2020, savings from the products shipped in the 10 years of the policy regime decline as these refrigerators are retired. The blue line shows the net savings in each year. The red line (NPV) represents these savings multiplied by the discount factor.

\footnotetext{
${ }^{12}$ Marginal tariffs in the agricultural sector are very close to average tariffs. We use the minimum average rate to assess cost efficiency.
} 
Figure 8. Annual National Consumer Financial Impacts for Refrigerators in High Efficiency Case

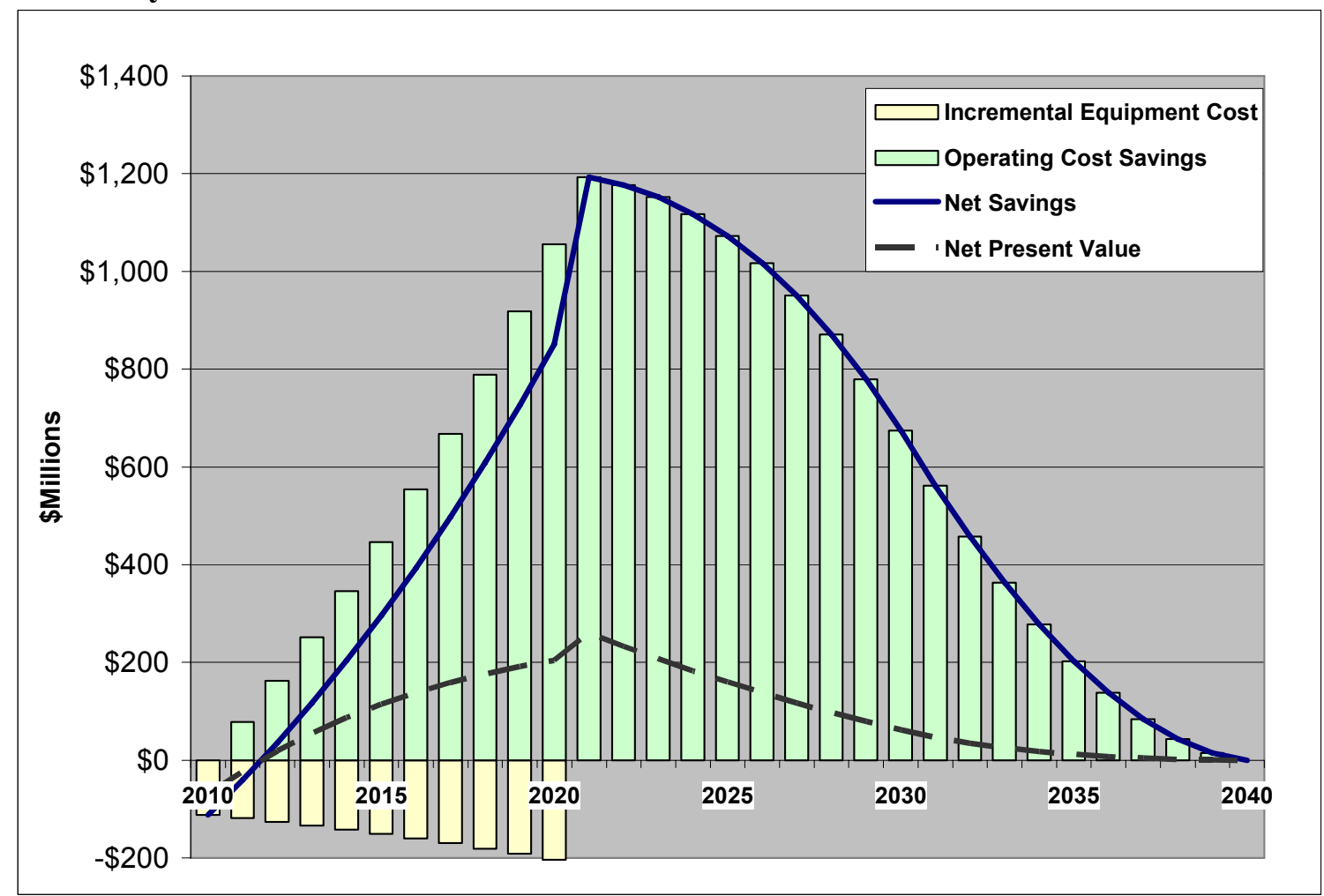

The total estimated NPV benefit to Indian consumers of the High Efficiency Case is shown by product in Table 15. The total NPV across all of the considered products is $\$ 5.5$ billion.

Table 15. Estimated Present Value of Costs and Benefits to Indian Consumers of the High Efficiency Case (\$ billion)

\begin{tabular}{|l|c|c|c|}
\hline Product & $\begin{array}{c}\text { Additional } \\
\text { Product Costs }\end{array}$ & $\begin{array}{c}\text { Electricity Cost } \\
\text { Savings }\end{array}$ & NPV \\
\hline Refrigerator & 0.6 & 1.9 & 1.3 \\
\hline Room air conditioner & 0.1 & 1.3 & 1.2 \\
\hline Motor & 0.3 & 0.7 & 0.5 \\
\hline Distribution transformer & 0.5 & 3.2 & 2.5 \\
\hline TOTAL & 1.5 & 7.0 & 5.5 \\
\hline
\end{tabular}

\section{Primary Energy Savings and Avoided Emissions}

Primary energy savings represent the energy use that would be avoided by the High Efficiency Case. In our main scenario, we assume that the current situation of electricity shortages is greatly relieved by 2010 (as envisioned by government plans). Thus, reduced electricity consumption from higher efficiency products does have an effect on electricity 
generation. To the extent that electricity shortages continue in the 2010-2020 period, the primary energy savings and avoided emissions would be lower than presented below, since much of the 'saved electricity' would be sold to a customer whose demand would otherwise be unmet. ${ }^{13}$ This meeting of unmet demand has other benefits, however, as discussed below.

The calculation of primary energy savings considers the heat rate -- the power plant fuel input needed to produce one unit of electricity, and transmission and distribution losses as a fraction of generation. According to data collected by the Indian Ministry of NonConventional Energy (GoI 2003), the heat rate of currently operating plants is 9621 $\mathrm{Btu} / \mathrm{kWh}$, equal to an input-to-generation factor of 2.82 . This factor is weighted over all electricity generation, including hydroelectric and nuclear (which have assumed factors of 0 and 3 , respectively). We calculated the average heat rate for each year in the forecast according to current plants in operation, in combination with planned additions to 2020 (GoI 2003). The T\&D loss rate is expected to drop from $32 \%$ today to $20 \%$ by 2020 (TERI 2001).

Table 16 shows the cumulative primary energy savings in the High Efficiency Case. Close to half of the savings come from more efficient refrigerators.

To calculate avoided $\mathrm{CO}_{2}$ emissions, we note that the current rate of $\mathrm{CO}_{2}$ emissions is 0.87 ton of $\mathrm{CO}_{2}$ per generated $\mathrm{MWh}$. This figure is expected to decrease to 0.79 $\mathrm{T}\left(\mathrm{CO}_{2}\right) / \mathrm{MWh}$ by 2020 due to installation of more efficient thermal plants (GoI 2003). Table 16 shows the cumulative avoided $\mathrm{CO}_{2}$ emissions in the High Efficiency Case.

Table 16. Estimated Primary Energy Savings and Avoided $\mathrm{CO}_{2}$ Emissions in the High Efficiency Case

\begin{tabular}{|l|c|c|}
\hline Product & MTOE & Million tons $\mathrm{CO}_{2}$ \\
\hline Refrigerator & 76.8 & 259.4 \\
\hline Room air conditioner & 23.0 & 77.6 \\
\hline Motor & 14.0 & 47.3 \\
\hline Distribution transformer & 45.3 & 153.3 \\
\hline TOTAL & 159.1 & 537.7 \\
\hline
\end{tabular}

\section{Benefit to Utilities}

The impact of the High Efficiency Case on utilities depends on the extent to which the current situation of electricity shortages is relieved in the 2010-20 period. If shortages are greatly reduced, reduced electricity consumption from higher efficiency products would decrease generation requirements and may allow for a slower growth in new capacity and capital expenditures. This impact reduces costs for utilities. We estimate a maximum

\footnotetext{
${ }^{13}$ Shortages generally occur at times of the day when demand is above average. If 'saved electricity' is saved during times when demand is below average, there may not be any unmet demand, and thus no opportunity to sell the 'saved electricity'.
} 
savings of about $30 \mathrm{TWh}$ from four products in 2020. An estimate of the impacts on generation from delivered energy savings is difficult without a detailed analysis of end use load shapes, but an order of magnitude estimate can be made by assuming constant loads for all products (simply dividing energy consumption by the number of hours in a year), yielding a power savings of about $3 \mathrm{GW}$. . At 1000 dollars cost per $\mathrm{kW}$ of generation capacity, 3 billion dollars worth of utility capital investments could be

On the other hand, the reduction in consumption reduces utility revenue. If electricity prices reflect the costs of supply, as for the commercial and industrial sector, the reduction in costs and the reduction in revenue may roughly cancel, and all savings benefits will accrue to the consumer.

If electricity prices are less than the costs of supply, as is currently the case for residential and agricultural consumers, the reduction in costs will be greater than the reduction in revenue. Utilities would see a net benefit in such a situation. For example, in the case of refrigerators, residential consumers would see a present (discounted) benefit of 1.9 billion dollars over the forecast period, based on a marginal electricity rate of 5.9 cents $/ \mathrm{kWh}$. Since the cost of production is $7.7 \mathrm{cents} / \mathrm{kWh}$, utilities would enjoy net savings (costs reduced less revenue lost) of 440 million dollars. Agricultural tariffs are even more highly subsidized. In this case, efficiency improvement is only cost effective from the consumer's point of view if incremental equipment costs are offset by incentive programs such as utility rebates. We assumed that utilities would bear half of the incremental equipment cost. If agricultural consumers pay only half the cost of production, then both costs and benefits of efficiency are shared equally between consumers and the utility. Based on this scenario, we calculated a Net Present Benefit of 65 million dollars to consumers. An equivalent amount would also be gained by utilities. Perhaps more importantly, the reduction in consumption of electricity in this highly subsidized sector contributes to the financial solvency of utilities.

If electricity shortages continue to be common in the post-2010 period, the impact of higher efficiency on utilities is more complicated to assess. During those times when there is a shortfall (typically during times of day when demand is high), the 'saved electricity' from higher efficiency could be sold to customers whose demand would otherwise be unmet. If subsidized electricity saved through higher efficiency can be sold to higher-tariff customers (such as industrial and commercial sectors), utilities would reap financial benefits.

\section{Indirect Benefit to the Economy and Government}

If shortages are much relieved, efficiency improvement in products used by residential and especially agricultural consumers can lower government subsidy payments to state electricity boards. In the case of refrigerators and residential air conditioners, lower consumption means that a greater percentage of the electricity produced is consumed by commercial and industrial customers, who pay more than the cost of production. For agricultural motors, lowered consumption means a reduction in operating costs spent to generate subsidized electricity. In this way, some portion of the current government 
subsidies for electricity could be transferred to a more cost-effective subsidy of high efficiency equipment.

If electricity shortages continue to be common, electricity consumption by customers whose demand would otherwise be unmet would allow for additional economic output (leading to higher employment) or would provide services to households. The additional economic output would yield higher tax revenues to the government, which could be used to improve public services. One indication of the financial benefit due to savings in the industrial and commercial sectors is in terms of electricity consumption and sales tax on products produced. A recent study for the state of Maharashstra (Sathaye 2004) estimates the sales tax generated from each $\mathrm{kWh}$ consumed at 5.9 Rs., or 11 cents per $\mathrm{kWh}$. This rate estimates the potential for increased sales tax for shortages avoided by implementation of efficiency measures.

In either case, reduced expenditure on electricity by consumers would allow for expenditure on other goods or services. Since electricity generation tends to be fairly capital-intensive, the transfer of expenditures from electricity to other goods or services could have a positive impact on employment.

Finally, reduced electricity generation due to improved efficiency would have local environmental benefits in terms of air quality.

\section{Variability of Results}

The main results for all four products are 159 MTOE of primary energy savings, 538 million tons of avoided carbon emissions and \$US 5.5 billion in net financial savings. As in any analysis, these results are highly dependent on assumptions and parameter definitions. In this section, we provide an indication of the important dependencies and the impact of alternative assumptions on the main results.

The amount of savings achievable for each product is based on due consideration of the baseline technologies used in India, well-established engineering options, and a rigorous assessment of cost-effectiveness. These estimates are not without uncertainty however. More importantly, we have assumed a scenario of complete market penetration of energy efficient technologies by 2010. Actual policy scenarios may achieve somewhat less than total market penetration. On the other hand, technologies may evolve that make even more aggressive measures cost effective.

The array of possible scenarios and their impact on the main results can be parameterized by allowing for variation in the actual per unit energy savings achieved, and the resulting incremental equipment cost. The impact on source energy savings from variations in achieved unit energy savings is trivial: the former simply scales as the latter. For example, if the per unit energy savings for refrigerators is only $80 \%$ of our estimate, the national source energy savings for this product will be $80 \%$ of 77 MTOE, or 62 MTOE. Likewise avoided emissions for this product would scale, from 259 million tons of $\mathrm{CO}_{2}$ to 207 million tons. 
For the calculation of Net Present Value of financial impacts, the situation is only slightly more complicated. Net Present Value is the difference of the present value of operating cost savings and incremental costs. Variability in incremental cost or per unit energy savings will impact each component of the calculation independently. The impact on the difference will vary from product to product. To demonstrate this point, we consider three scenarios for each of the two main input variables independently: where the variable is $50 \%$ lower than our analysis, where it is equal to our analysis, and where it is $50 \%$ higher than our analysis. The results of this sensitivity are given in Table 17 .

Table 17. Impact on Net Present Value of Financial Impacts from Variability in Per Unit Product Incremental Cost and Energy Savings (Billions of \$US)

\begin{tabular}{|l|c|c|c|}
\hline & $\begin{array}{c}\text { Energy Savings- } \\
50 \%\end{array}$ & $\begin{array}{c}\text { Energy Savings } \\
+0 \%\end{array}$ & $\begin{array}{c}\text { Energy Savings } \\
+50 \%\end{array}$ \\
\hline Equipment Cost $-50 \%$ & 2.7 & 6.3 & 9.8 \\
\hline Equipment Cost $+0 \%$ & 2.0 & $\mathbf{5 . 5}$ & 9.0 \\
\hline Equipment Cost $+50 \%$ & 1.2 & 4.7 & 8.2 \\
\hline
\end{tabular}

In this sensitivity analysis we have considered the scenario where all products have the same variability. In the extreme low case, NPV is 1.2 billion dollars; while less than a fourth of our estimate, the sum is still significant. This case can be considered to be a lower limit.

The national discount rate is also an important parameter in calculation of Net Present Value. The total of 5.5 billion US dollars was calculated assuming a discount rate of $10 \%$. A discount rate of $7 \%$ yields an NPV of 9.2 billion \$US, while a discount rate of $15 \%$ yields 2.5 billion $\$$ US.

Finally, our estimates are dependent on assumption of growth in product sales, which are determined according to recent historical trends. Of these, the growth rates of refrigerator and air conditioner sales are likely to be the most volatile, as these are dependent on the disposable income of a large segment of the population, which is in turn driven by the dramatic growth of GDP per capita in India. Growth in sales of motors and distribution transformers is likely to be less volatile. Our analysis estimated a sales growth rate of $5.9 \%$ for refrigerators and $10 \%$ for air conditioners. We consider a 'low growth' scenario in which growth rates are 3\% and 5\% respectively, and a 'high growth' scenario with rates of $10 \%$ and $15 \%$. The low growth case results in primary energy savings of 137 MTOE, while the 'high growth' case energy savings is 199 MTOE.

\section{Conclusion}

The study described in this report employed the methodology of life-cycle cost analysis and national energy and environmental impact accounting in order to provide detailed estimates of the potential benefits of equipment efficiency programs in India. The equipment studied -- household refrigerators, room air conditioners, industrial and 
agricultural motors and distribution transformers -- contribute significantly to national electricity consumption in India, and they afford considerable opportunity for efficiency increases through cost-effective design improvement. These products do not represent an exhaustive set of equipment for which efficiency programs may be attractive. Instead, they are best seen as examples which demonstrate the cost-effectiveness and scale of impacts of such programs in general. In addition, sufficient data are available to enable quantitative analyses which can be considered by policymakers and technical staff empowered to support implementation of specific programs.

Major conclusions are:

The products studied - domestic refrigerators, room air conditioners, industrial and agricultural motors and distribution transformers -- all represent attractive candidates for efficiency programs in India, in terms of potential electricity savings.

Substitution of baseline models of these equipment with high-efficiency models is highly cost-effective from a consumer perspective, given current estimates of incremental equipment prices and the projected future price of electricity .

Substitution of baseline equipment in India with high-efficiency models that minimize consumer costs over the lifetime of the equipment would result in an average per-unit relative savings of:

$45 \%$ for domestic refrigerators

$6 \%$ for room air conditioners

$20-39 \%$ for industrial motors (percent reduction in losses)

$12 \%$ for agricultural motors (percent reduction in losses)

$56 \%-62 \%$ for distribution transformers

Assuming that an efficiency program achieves target levels in India for all products shipped between 2010 and 2020, primary energy savings of the programs would total:

77 million tons of oil equivalent (MTOE) for domestic refrigerators

23 MTOE for room air conditioners

14 MTOE for industrial and agricultural motors

45 MTOE for distribution transformers

The avoided carbon dioxide emissions would total:

259 million tons for domestic refrigerators

78 million tons for room air conditioners

47 million tons for industrial and agricultural motors

153 million tons for distribution transformers

Net Present Value benefit to consumers (net benefits discounted to present year) would total:

1.3 billion \$US for domestic refrigerators 


\section{2 billion \$US for room air conditioners}

0.5 billion \$US for industrial and agricultural motors

2.5 billion $\$$ US for distribution transformers

In addition to financial benefits gained by consumers, significant additional benefits could be gained from efficiency programs in India by avoidance of power outages currently experienced throughout the country as a result of loads that exceed system capacity.

\section{ACKNOWLEDGEMENTS}

The research presented in this report benefited greatly from discussion, review and data sources generously provided by colleagues with wide knowledge in the field of energy efficiency, but particularly with experience in the Indian context. Mr. Ramaswamy of BEE was very helpful in providing data regarding distribution transformer efficiency levels and cost estimates. Denise Knight of IIEC provided critical data regarding motor efficiency levels, costs and market segmentation. Stephane de la Rue du Can of LBNL provided access to IEA electricity forecasts used in the regional extension analysis. Jayant Sathaye of LBNL and Amol Phadke of Energy Resources Group, UC Berkeley were very helpful in sharing results of their recent work with the state of Maharashtra. We thank Meeta Mehra of TERI for the details she provided on Indian power sector demand projects. We are also grateful to Puneet Chitkara of TERI and Mahesh Patankar of IIEC for their useful discussions. Finally, Jayant Sathaye of LBNL and Mayur Karmarkar of ICA Mumbai provided review and many useful comments to drafts of the report. 


\section{REFERENCES}

Banerjee, R. and Parikh, J.K. (1993). Demand Side Management in Power Planning - An Exercise for HT Industries in Maharashtra. Economic and Political Weekly, August 714, 1993.

Bhatia, P. (1999). Development of Energy-Efficiency Standards for Indian Refrigerators. ASHRAE Transactions: Research.

CEA (2002-2003) Indian Central Electricity Authority -Annual issues of General Review Statistics

CLASP (2003). Report on GHG Emissions Reduction Estimation - Indian Standards and Labeling Program. Washington, D.C., USEPA, USAID.

Economist Intelligence Unit (2005). Executive Briefing: Egypt

Euromonitor (2003). Domestic Electrical Appliances in India.

European Commission (2000) Cold II - The Revision of Energy Labelling and Minimum Energy Efficiency Standards for Domestic Refrigeration Appliances.

Gobi International (2002). Refrigerators - The International Market 2002.

GoI (2003). Baseline for renewable energy projects under clean development mechanism. New Delhi, Government of India Ministry of Non-Conventional Energy.

Harrington, L. (2004). Energy Labelling and Energy Efficiency Standards in India, Indian Bureau of Energy Efficiency.

IEEMA (2003) Indian Electrical and Electronics Manufacturers' Association - IEEMA Journal - Production Statistics. http://www.ieema.org

IIEC (1999) Market and Technology Assessment for Energy Efficient Motors in India.

IMRB (2004). Baseline Report on Data Collected From Manufacturers, Indian Bureau of Energy Efficiency.

McNeil, M.A and Letschert, V.E. (2005). Forecasting Electricity Demand in Developing Countries: A Study of Household Income and Appliance Ownership. European Consortium for an Energy Efficient Economy, Mandelieu, France.

Nadel, S. S., M., Greenberg, S., Katz, G. and de Almeida, A.T. (1992). Energy Efficient Motor Systems - A Handbook on Technology, Program, and Policy_Opportunities, American Consortium for an Energy Efficient Economy. 
The News International Pakistan (2005). Refrigerator sales stand at 175,000. Karachi, Pakistan.

ORNL (1995) The Feasibility of Replacing or Upgrading Utility Distribution Transformers During Routine Maintenance, ORNL-6804/R1, Oak Ridge National Laboratory, 1995

Planning Commission (2002). Annual Report (2001-2002) on the Working of State Electricity Boards \& Electricity Departments.

Planning Commission (2004). India: Vision 2020: Report of the Committee on India Vision 2020, New Delhi

Sathaye (2004) J. Sathaye and A. Phadke. Electricity End-use Efficiency: Means to Reduce Electricity Shortage With Economic Benefits. Synergy for Energy, Ahmedabad, India, October 2004.

TERI (2001). Directions, Innovations, and Strategies for Harnessing Action for Sustainable Development (DISHA). New Delhi, Tata Energy Research Institute.

USDOE (1997) Technical Support Document for Energy Conservation Standards for Room Air Conditioners. Sept. 1997.

USDOE (1997a) Federal Register Vol 62 No. 185 Part III - Energy Conservation Program for Consumer Products: Conservation Standards for Room Air Conditioners; Final Rule.

USDOE (1999) Federal Register Vol. 64 No. 192 Part III - Energy Efficiency Program for Certain Commercial and Industrial Equipment: Test Procedures, Labeling and Certification Requirements for Electric Motors; Final Rule

USDOE (2004) Technical Support Document for Energy Conservation Standards for Distribution Transformers - Advance Notice of Proposed Rulemaking. July 2004. 


\section{Appendix A: Calculating Marginal Electricity Rates}

An understanding of marginal electricity rates is crucial in assessing potential financial impacts from efficiency programs. The estimation of marginal tariffs for residential, commercial, industrial and agricultural customers allows for the calculation of the operating cost savings yielded by more efficient equipment.

The marginal price of electricity is the price per $\mathrm{kWh}$ of the last unit of electricity used by the consumer, as opposed to the average price, which is the total electricity bill (including fixed charges) divided by the total electricity used. The distinction is important, because a reduction in consumption due to a particular piece of efficient equipment will generally not affect fixed charges, but will reduce the usage in the highest category.

This study made an estimate of consumer marginal electricity prices by analyzing the tariff structures provided by a sample of State Electricity Boards (SEBs), in combination with estimates of household or business consumption. The marginal rate is taken to be the price of electricity for the block in which the average household or business consumption falls. These rates and the block definitions differ significantly from one state to the next. Therefore, the marginal rate had to be identified on a state-by-state basis. National average results were then obtained by weighting according to state electricity consumption.

India's power sector continues to be dominated by Central and State government-owned organizations. In most of the cases, the SEB is the generator, transmitter and distributor of power. Most of the tariffs have been collected from State Electricity Board websites.

Table A-1 presents the states for which some tariffs were available and also their population characteristics. Of the 28 Indian states and 7 union territories, tariff data were available for 15 states, which represent $83 \%$ of the total population (see table at end of this appendix). The calculation of national marginal electricity rates for the residential, commercial, industrial and agricultural sectors is summarized in Table A-1. The national sectoral rates are the average over all states for which tariffs were available, weighted by sectoral electricity sales in each state (electricity sales data from Planning Commission 2002). 
Table A-1 - Sectoral Marginal Prices by State

\begin{tabular}{|c|c|c|c|c|c|c|c|c|}
\hline \multirow{3}{*}{ State } & \multicolumn{4}{|c|}{ Electricity Sales } & \multicolumn{4}{|c|}{ Marginal Electricity } \\
\hline & Res. & Com. & Ind. & Ag. & Res. & Com. & Ind. & Ag. \\
\hline & \multicolumn{4}{|c|}{ GWh / year } & \multicolumn{4}{|c|}{$\$ 2004 / \mathrm{kWh}$} \\
\hline Andhra Pradesh & 6955 & 1291 & 6786 & 11222 & 0.069 & 0.136 & 0.081 & 0.004 \\
\hline Assam & 648 & 170 & 287 & 49 & 0.065 & 0.104 & $\mathrm{~N} / \mathrm{A}$ & 0.073 \\
\hline Bihar & 1068 & 428 & 3759 & 1549 & 0.049 & $\mathrm{~N} / \mathrm{A}$ & 0.089 & $\mathrm{~N} / \mathrm{A}$ \\
\hline Gujarat & 3122 & 889 & 9200 & 14507 & 0.078 & 0.102 & 0.081 & 0.015 \\
\hline Haryana & 2359 & 446 & 2104 & 5171 & $\mathrm{~N} / \mathrm{A}$ & N/A & 0.092 & $\mathrm{~N} / \mathrm{A}$ \\
\hline Himachal & 657 & 160 & 1225 & 18 & 0.028 & $\mathrm{~N} / \mathrm{A}$ & 0.049 & 0.011 \\
\hline Rarnatàka & 4120 & 1184 & 3842 & 6457 & 0.066 & 0.136 & 0.070 & $\mathrm{~N} / \mathrm{A}$ \\
\hline Kerala & 4946 & 895 & 3767 & 410 & 0.052 & 0.179 & 0.070 & 0.014 \\
\hline Madhya Prades & 3785 & 885 & 6611 & 10200 & 0.065 & 0.092 & 0.114 & 0.052 \\
\hline Maharashtra & 7521 & 1575 & 16894 & 10937 & 0.063 & 0.089 & 0.054 & 0.024 \\
\hline Meghalaya & 137 & 47 & 118 & 0 & 0.041 & 0.090 & 0.079 & 0.022 \\
\hline Orissa & 2166 & 429 & 2583 & 196 & 0.056 & N/A & 0.069 & 0.024 \\
\hline Punjab & 4074 & 902 & 8295 & 8200 & 0.075 & 0.090 & $\mathrm{~N} / \mathrm{A}$ & $\mathrm{N} / \mathrm{A}$ \\
\hline Tamil & 6402 & 1935 & 12064 & 9066 & 0.028 & 0.087 & 0.072 & 0.074 \\
\hline Uttár Pradesh & 7341 & 1911 & 5040 & 4965 & 0.060 & 0.087 & 0.100 & 0.043 \\
\hline West Bengal & 2700 & 1179 & 2827 & 1360 & 0.054 & $\mathrm{~N} / \mathrm{A}$ & 0.072 & $\mathrm{~N} / \mathrm{A}$ \\
\hline Total/ & 58001 & 14326 & 85402 & 84307 & 0.059 & 0.107 & 0.076 & 0.032 \\
\hline
\end{tabular}

\section{Residential Tariffs}

All residential tariffs surveyed are progressive, that is, the more the household consumes the more the kWh (unit) costs, as shown in Figure A-1. The bill is the sum of the fixed charges each month and the energy charges on the basis of a maximum load of $1 \mathrm{~kW}$. Fixed charges for residential customers are negligible compared to the total bill except for low consumers of electricity.

In calculating marginal electricity prices for each state, we assume an average monthly household consumption of $112 \mathrm{kWh}$. This number is the average consumption in a sample of 369 "all-electric" homes (AEH) in Karnataka State representing the 963,000 total AEH households served by the Karnataka Electricity Board (Narasimha 2001). These households are most appropriate to characterize electrical consumption for households owning a refrigerator. All-electrical homes are a group of households connected to $3.5 \mathrm{kVA}$ load and owning appliances, as opposed to the majority of connections which carry a $1.15 \mathrm{kVA}$ load. The saturation rate for refrigerators in these households was found to be $58 \%$. By comparison, only two percent of the non-AEH households was found to own a refrigerator. 
Figure A-1 - Monthly Residential Electricity Bill vs. Consumption

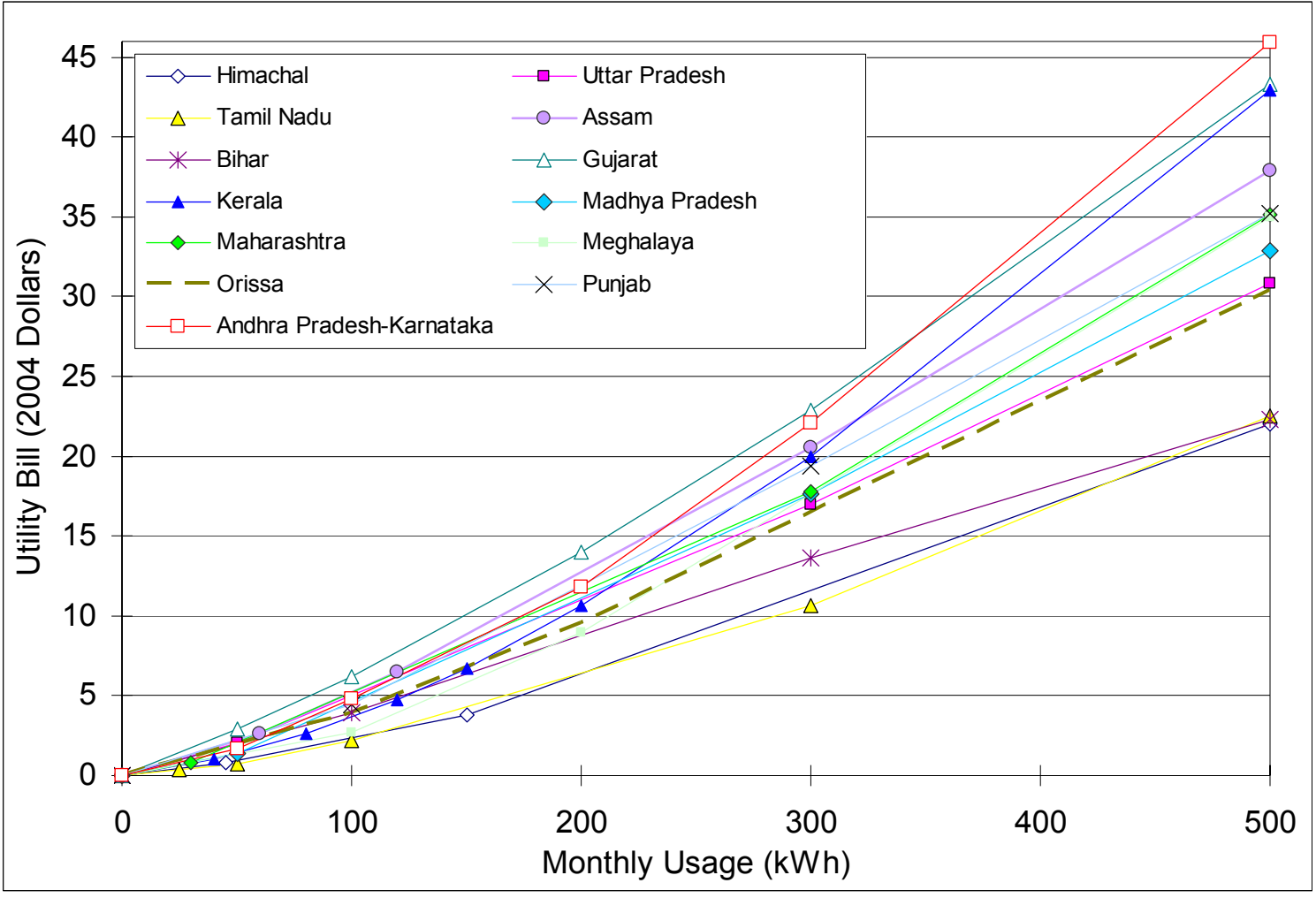

Marginal electricity price for a $112 \mathrm{kWh}$ monthly consumption was determined for each state, and the national average of 5.9 USD cents per $\mathrm{kWh}$ was calculated by taking an average of all states for which tariff data were available, weighted by each state's residential electricity sales. The assumption of $112 \mathrm{kWh}$ monthly consumption introduces some uncertainty in our estimation of average marginal rates, due to variability in consumption among households. Due to the tariff structure, however, this variability is reasonably small. In order to evaluate the uncertainty introduced by the average household consumption, we recalculated the average marginal tariff using household consumption over the range of $50 \mathrm{kWh}$ to $250 \mathrm{kWh}$ per month. The marginal tariff calculated varies by less than one USD cent over this entire range, giving confidence that the rate calculated using $112 \mathrm{kWh}$ per month is close to the actual marginal rate.

\section{Commercial Tariffs}

Commercial tariffs were available for only 11 of 28 states and union territories. These States represent $67 \%$ of the total population, but cover $77 \%$ of commercial electricity sales (SEB sales only) in India. The structure of the tariffs is represented in Figure A-2. 
Figure A-2 - Monthly Commercial Electricity Bill vs. Consumption

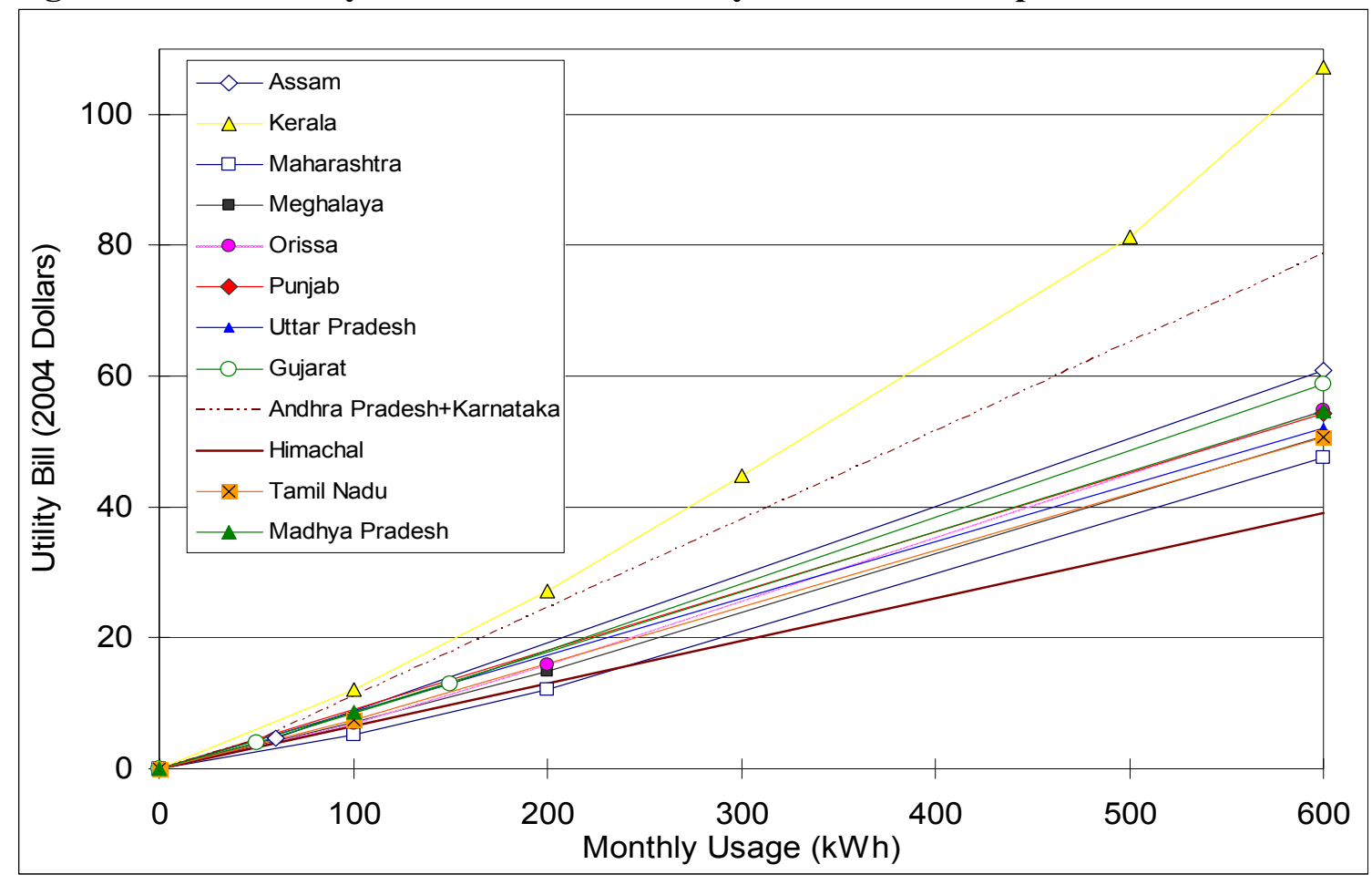

Commercial rates are generally much higher than residential rates, and have less dependency on monthly consumption. As for residential rates, determination of the cost of the last $\mathrm{kWh}$ consumed requires an estimate of the average consumption of commercial buildings affected by efficiency programs, such as might be impacted by a minimum efficiency standard for air conditioners. A rough estimate based on Kerala electricity board data and the annual report of the Indian Energy Commission gave 800 $\mathrm{kWh} /$ month and per connection, which is quite high for a small business. Prices were therefore determined for a more likely monthly consumption of $500 \mathrm{kWh} .{ }^{14}$ Applying this average consumption in the way that was done for residential prices -- the average was weighted with the commercial consumption -- yields an average price for the country of 10.7 USD cents per kWh.

The appropriate average consumption used is speculative, but marginal commercial electricity rates are highly insensitive to the precise value of consumption, except for very low consumption levels. In only two of the states surveyed (Kerala and Orissa) was there any dependence of marginal rates of consumption above $300 \mathrm{kWh}$ per month. Therefore, we are confident that the marginal rate calculated using $500 \mathrm{kWh}$ is close to the actual marginal rate paid for the average Indian commercial consumer.

${ }^{14}$ Refinement of the estimate of monthly consumption for businesses likely to be affected by efficiency standards is an important area for further research.. 


\section{Industrial Tariffs}

Industrial tariffs were collected for 13 states. The structure of industrial tariffs differs significantly from those of the other sectors. Tariffs are dependent on whether the customer uses a low tension (HT) or low tension (LT) connection, and according to load $(\mathrm{kW})$. Within these categories, however, marginal tariffs are relatively insensitive to consumption. In order to assess marginal industrial tariffs, some assumption about monthly consumption was necessary. Consumption was estimated assuming that the bulk of electricity consumption used by the customer was due to electric motors. Therefore, we estimated total consumption in terms of the total horsepower of installed motors. For each range of horsepower, we calculated monthly consumption assuming that motors are running 12 hours per day ( 1 and a half shifts), for 20 days per month. The average load per motor was assumed to be 0.8 .

Table A-2 shows the marginal electricity rate for a wide range of motor horsepower. Rates for low tension were used unless there was no LT rate available for the given load. A load category of $40 \mathrm{HP}$ was used for the analysis of high-efficiency motor impacts. This corresponds to the situation where several motors of $10 \mathrm{HP}$ are installed. Rates are generally flat over several categories of load. Therefore, while there is a great deal of uncertainty in the average load of industrial enterprises that would participate in an efficiency program, this uncertainty has little impact on marginal rates.

Table A-2 - Marginal Industrial Tariffs by Load and State

\begin{tabular}{|l|l|l|l|l|l|l|}
\cline { 2 - 7 } \multicolumn{1}{c|}{} & $8 \mathrm{HP}$ & $20 \mathrm{HP}$ & $40 \mathrm{HP}$ & $70 \mathrm{HP}$ & $110 \mathrm{HP}$ & $150 \mathrm{HP}$ \\
\hline Haryana & 9.22 & 9.22 & 9.22 & 9.22 & 8.87 & 8.87 \\
Himachal Pradesh & 4.34 & 4.34 & 4.88 & 4.88 & 4.88 & 5.86 \\
Uttar Pradesh & 9.54 & 9.54 & 9.98 & 9.98 & 7.81 & 7.81 \\
Gujarat & 7.59 & 8.13 & 8.13 & 8.13 & 8.13 & 8.13 \\
Madhya Pradesh & 6.51 & 8.68 & 11.39 & 11.39 & 8.65 & 8.65 \\
Maharashtra & 5.42 & 5.42 & 5.42 & 5.42 & 5.42 & 7.27 \\
Andhra Pradesh & 8.13 & 8.13 & 8.13 & 8.13 & 8.13 & 7.59 \\
Karnataka & 6.51 & 6.51 & 7.05 & 7.05 & 7.05 & 8.13 \\
Kerala & 7.05 & 7.05 & 7.05 & 7.05 & 7.05 & 6.51 \\
Tamil Nadu & 5.42 & 7.16 & 7.16 & 7.16 & 7.16 & 7.59 \\
Bihar & 8.46 & 8.46 & 8.89 & 8.89 & 3.86 & 3.86 \\
Orissa & 6.94 & 6.94 & 6.94 & 6.94 & 6.94 & 6.94 \\
West Bengal & 7.33 & 8.05 & 7.16 & 7.16 & 7.16 & 5.86 \\
Meghalaya & 7.92 & 7.92 & 7.92 & 7.92 & 7.92 & 4.55 \\
\hline Weighted Average & $\mathbf{6 . 7 8}$ & $\mathbf{7 . 3 3}$ & $\mathbf{7 . 6 2}$ & $\mathbf{7 . 6 2}$ & $\mathbf{6 . 9 8}$ & $\mathbf{7 . 4 0}$ \\
\hline
\end{tabular}


The national average marginal price for industrial customers is calculated by taking the average marginal price at the $40 \mathrm{HP}$ level for each state, weighted by the total industrial electricity consumption (from SEBs) of each state. The resulting national marginal price for industrial customers is 7.6 USD cents per $\mathrm{kWh}$.

\section{Agricultural Tariffs}

Of all sectors studied, tariffs in the agricultural sector are the lowest, and vary the least according to monthly consumption. Agricultural tariffs were available for 11 states. Marginal agricultural tariffs for these states are shown for a range of consumption level in Table A-3. The national marginal rate is an average over all states, weighted by each state's agricultural electricity sales (from SEBs). For the purposes of calculating efficiency benefits, we assumed marginal rates for the 60 to $100 \mathrm{kWh}$ consumption range, which average $3.2 \mathrm{USD}$ cents per $\mathrm{kWh}$.

Table A-3 - Marginal Agricultural Tariffs by Monthly Consumption and State

\begin{tabular}{|l|l|l|l|l|l|}
\cline { 2 - 6 } \multicolumn{1}{c|}{} & $15-30 \mathrm{kWh}$ & $\begin{array}{l}30-60 \\
\mathrm{kWh}\end{array}$ & $60-100 \mathrm{kWh}$ & $\begin{array}{l}100-200 \\
\mathrm{kWh}\end{array}$ & $>200 \mathrm{kWh}$ \\
\hline Andhra Pradesh & 0.004 & 0.004 & 0.004 & 0.004 & 0.011 \\
Assam & 0.036 & 0.057 & 0.073 & 0.073 & 0.073 \\
Gujarat & 0.015 & 0.015 & 0.015 & 0.015 & 0.015 \\
Himachal Pradesh & 0.011 & 0.011 & 0.011 & 0.011 & 0.011 \\
Kerala & 0.014 & 0.014 & 0.014 & 0.014 & 0.014 \\
Madhya Pradesh & 0.052 & 0.052 & 0.052 & 0.052 & 0.052 \\
Maharashtra & 0.024 & 0.024 & 0.024 & 0.024 & 0.024 \\
Meghalaya & 0.022 & 0.022 & 0.022 & 0.022 & 0.022 \\
Orissa & 0.024 & 0.024 & 0.024 & 0.024 & 0.024 \\
Tamil Nadu & 0.074 & 0.074 & 0.074 & 0.087 & 0.087 \\
Uttar Pradesh & 0.043 & 0.043 & 0.043 & 0.043 & 0.043 \\
\hline Weighted & & $\mathbf{0 . 0 3 2}$ & $\mathbf{0 . 0 3 2}$ & $\mathbf{0 . 0 3 4}$ & $\mathbf{0 . 0 3 5}$ \\
Average & $\mathbf{0 . 0 3 2}$ & $\mathbf{0}$ & & \\
\hline
\end{tabular}




\section{REFERENCES}

\section{Electricity prices:}

Andhra Pradesh $\quad \underline{\underline{\text { http://www.ercap.org/HIGHLIGHTS }} \text { TARIFF FOR THE YEAR }}$

Assam http://www.aerc.nic.in/

Bihar

Gujarat $\quad$ http://www.gseb.com/

Himachal Pradesh http://www.hpseb.com

Karnataka $\quad$ http://www.kerc.org

Kerala $\quad$ http://www.kseboa.org/

Madhya Pradesh $\quad$ http://www.mp.nic.in/energy/mpseb/mainpage.html

Maharashtra http://www.msebindia.com

Meghalaya http://meseb.nic.in/

Orissa $\quad$ http://www.orierc.org/

Punjab $\quad$ http://www.psebindia.org/

TamilNadu http://www.tn.gov.in/

Uttar Pradesh $\quad$ http://www.uperc.org/Tariff_UPPCL_FY04.zip

West Bengal http://www.wbseb.gov.in/tariff_domesticpurpose.htm

Narasimha Murthy, K.V., Gladys D. Sumithra, Amulya K.N. Reddy, 2001. End-uses of electricity in households of Karnataka State, India, Energy for Sustainable Development, Volume 5 no. 3.

http://www.ieiglobal.org/ESDVoL5No3/karnatakahouseholds.pdf 


\section{Appendix B: Calculating National Impacts}

The total stock and vintage of appliances in any given year is needed in order to calculate national energy consumption and savings. The stock is calculated using a straightforward accounting method that takes each year's sales as input. For each year, some fraction of the cohort installed in previous years remains, according to a survival function. From the survival function Surv(age) and shipments forecast Shipments(year), the remaining stock in each year is given by:

$$
\operatorname{Stock}(\text { year })=\sum_{\text {age }=1}^{4 L / 3} \operatorname{Shipments}(\text { year }- \text { age }) \times \operatorname{Surv}(\text { age })
$$

Total energy consumption by consumers in the Base Case and in the High Efficiency Case is calculated by multiplying the remaining stock from each cohort by the unit energy consumption. For each product, the site energy consumption of the stock in each year is therefore given by

SiteEnergy $($ year $)=\sum_{\text {age }=1}^{4 L / 3} \sum_{\text {class }=D C, F F}$ Shipments $_{\text {Class }}($ year - age $) \times \operatorname{Surv}($ age $) \times U E C_{\text {Class }}($ year - age $)$

where the sum is over both product classes. Site energy savings is given by the same formula, where the energy consumption term is replaced by $\triangle U E C$, and

$$
\triangle U E C=U E C^{\text {PolicyCase }}-U E C^{\text {BaseCase }}
$$

The Net Present Value (NPV) to consumers represents the net financial savings to consumers yielded by use of the High Efficiency Case products, discounted to the present year (2005). Financial impacts are calculated at the national level using the aforementioned shipments and stock forecasts. Incremental equipment costs for each year are given by

$$
\Delta E C(\text { year })_{\text {NATION }}=\Delta E C(\text { year }) * \text { Shipments }(\text { year })
$$

Likewise, national operating costs are given according to the stock by

$$
\Delta O C_{\text {NATION }}(\text { year })=\Delta O C(\text { year }) * \text { Stock }(\text { year })
$$

where the unit operating cost savings varies from year to year due to changes in the marginal electricity price,

$$
\triangle O C(\text { year })=\Delta U E C \times \text { MargElecPrice (year) }
$$

The net savings in each year arises from the difference in incremental equipment and operating costs in the High Efficiency Case versus the Base Case, $\triangle E C_{N A T I O N A L}$ and $\triangle O C_{\text {NATIONAL. Net }}$ Nesent Value of the High Efficiency Case is then defined as the sum 
over the forecast period of the net national savings in each year, multiplied by the appropriate national discount rate

$$
N P V=\sum_{\text {year }=y_{0}} \frac{\Delta O C_{\text {NATIONAL }}(\text { year })-\Delta E C_{\text {NATIONAL }}(\text { year })}{\left(1+D R_{N}\right)^{\left(\text {year }-y_{0}\right)}}
$$

The calculation of primary energy savings considers the heat rate, the power plant fuel input needed to produce one unit of electricity, and transmission and distribution losses as a fraction of generation. The primary energy savings in each year is given by

$$
\text { PrimarySavings(year) }=\text { SiteSavings(year) } x \text { HeatRate (year) } /(1+\text { TDRate(year)) }
$$




\section{Appendix C: Primary Energy and Emissions for Indian Power Sector}

\section{Heat Rate and Emission Factor}

Heat rates and $\mathrm{CO}_{2}$ emissions factors for installed generation in India (as of 2002) are taken from a governmental (GoI 2003). For each region, power plants are classified under their generation mode (coal, gas, lignite, diesel, hydro, nuclear). For each plant, data are given for installed capacity, fuel type, gross generation gross, net heat rate and $\mathrm{CO}_{2}$ emissions.

In case of gas power plants the heat rate is taken from generation norms (CEA 20032003). In the report, the emission factors (EF) were calculated was follows:

$$
\begin{gathered}
E F\left(\mathrm{~kg}_{\mathrm{CO} 2} / \mathrm{MWh}\right)=\text { HeatRate }(\mathrm{kcal} / \mathrm{MWh}) * E F_{\text {fuel }}\left(\mathrm{kg}_{\mathrm{CO} 2} / \mathrm{kg}_{\text {fuel }}\right) / \text { Calorific value } \\
\left(\mathrm{kcal} / \mathrm{kg}_{\text {fuel }}\right)
\end{gathered}
$$

Calculations were made by region and state and then by generation type. The sample of plants represents over 85 coal plants and 33 gas plants all over the country. A heat rate factor of 3 was assumed for nuclear generation. $\mathrm{CO}_{2}$ Emission factors for nuclear and hydroelectric generation were assumed to be zero. All the averages are weighted with the electricity generation. Table $\mathrm{C}-1$ summarizes the results by region. Emission factors are given in $\mathrm{kg}\left(\mathrm{CO}_{2}\right) / \mathrm{MWh}$.

The weighted average heat rate of currently operating plants in India is $9621 \mathrm{Btu} / \mathrm{kWh}$, equal to a heat rate factor of 2.82. The weighted average $\mathrm{CO}_{2}$ emissions rate is $846 \mathrm{~kg}$ per MWh.

Table C-1 - 2002 Fuel Mix and Emission Factor by Region

\begin{tabular}{|l|c|c|c|c|c|c|c|c|}
\hline & $\begin{array}{c}\text { Thermal } \\
\mathrm{CO}_{2} \\
\text { Emission } \\
\text { Factor } \\
(\mathrm{kg} / \mathrm{MWh})\end{array}$ & $\begin{array}{c}\text { Thermal } \\
\text { Heat } \\
\text { Rate }\end{array}$ & $\begin{array}{c}\text { Thermal } \\
\text { Percent } \\
\text { of Elec } \\
\text { Gen }\end{array}$ & $\begin{array}{c}\text { Nuclear } \\
\text { Percent } \\
\text { of Elec } \\
\text { Gen }\end{array}$ & $\begin{array}{c}\text { Hydro } \\
\text { Percent } \\
\text { of Elec } \\
\text { Gen }\end{array}$ & $\begin{array}{c}\text { Elec } \\
\text { Gen } \\
(\mathrm{TWh})\end{array}$ & $\begin{array}{c}\mathrm{CO}_{2} \\
\text { Emission } \\
\text { factor } \\
(\mathrm{kg} / \mathrm{MW} \\
\mathrm{h})\end{array}$ & $\begin{array}{c}\text { Overall } \\
\text { Heat } \\
\text { Rate }\end{array}$ \\
\hline $\begin{array}{l}\text { Norther } \\
\mathrm{n} \\
\text { Region }\end{array}$ & 1071 & 3.45 & 76 & 5 & 19 & 138 & 705 & 2.7 \\
\hline $\begin{array}{l}\text { Western } \\
\text { Region }\end{array}$ & 1022 & 3.04 & 91 & 4 & 5 & 152 & 933 & 3.1 \\
\hline $\begin{array}{l}\text { Souther } \\
\mathrm{n} \\
\text { Region }\end{array}$ & 1027 & 3.13 & 74 & 4 & 22 & 121 & 760 & 2.4 \\
\hline $\begin{array}{l}\text { Eastern } \\
\text { Region }\end{array}$ & 1379 & 3.43 & 86 & 0 & 14 & 57 & 1192 & 3.0 \\
\hline $\begin{array}{l}\text { NE } \\
\text { Region }\end{array}$ & 627 & 2.79 & 65 & 0 & 35 & 5 & 210 & 1.0 \\
\hline India & 1231 & 3.20 & 83 & 4 & 14 & 474 & 846 & 2.8 \\
\hline
\end{tabular}


An estimate of heat rates and $\mathrm{CO} 2$ emissions factors during the period after 2010 relies on plans for the expansion of each type of generation in order to meet the expected rise of electricity production in the coming years. According to Planning Commission (2004), electricity generation will reach $1551 \mathrm{TWh}$ by 2020 . This level will be achieved by increase in capacity of existing plants and the construction of new plants in 2002-2012, as projected for the periods corresponding to the $10^{\text {th }}$ and $11^{\text {th }} 5$-year plans.

Emissions are projected for each of these years in (GoI 2003). Heat rates of added capacity were estimated according to the fuel mix and plant type projected for construction or increase in capacity. From 2002-2012, 42\% of new generation is expected to come from coal, 10\% from lignite and 34\% from hydroelectric, with the balance coming from oil, natural gas and nuclear plants.

During the period 2002-2007, most of the additions to capacity will be from thermal plants, with significant additions in hydroelectric, nuclear, and other renewable sources. Therefore, the average heat rate of the system will increase somewhat before peaking in fiscal year 2007-2008, and beginning a steady decline. Figure C-1 shows the composition of generation between 2002 and 2020, along with the trajectory of the heat rate factor. Similarly, the emissions factor of $846 \mathrm{~kg}\left(\mathrm{CO}_{2}\right) / \mathrm{MWh}$ is expected to decrease to $729 \mathrm{~kg}\left(\mathrm{CO}_{2}\right) / \mathrm{MWh}$ by 2020 due to installation of more efficient thermal plants.

\section{Figure C-1 Generation Fuel Mix and Heat Rate Factor 2002-2020}

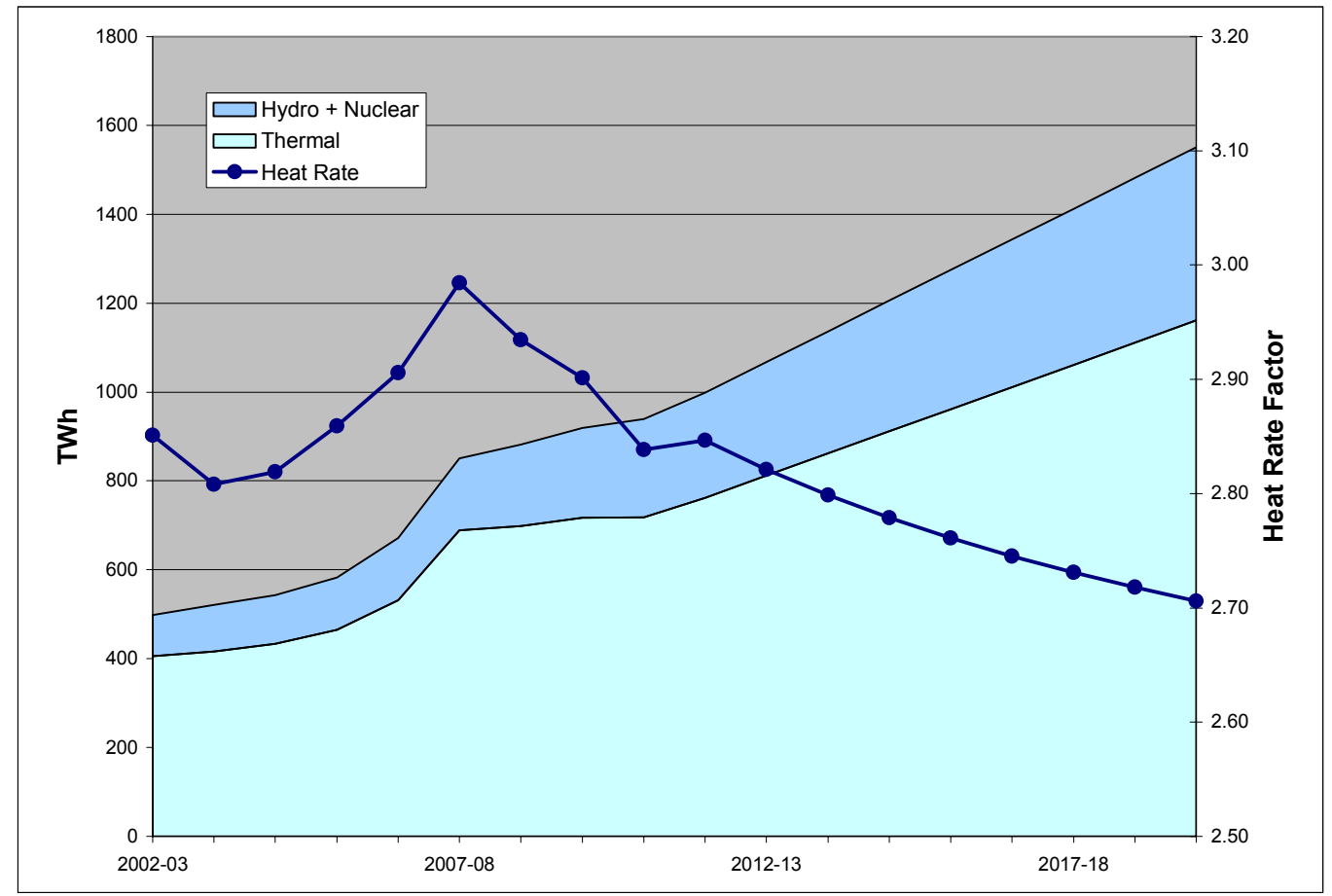

Transmission and Distribution Losses 
A revised estimation from the Planning Commission for the year 2001-2002 (Planning Commission 2002) gives transmission and distribution losses state by state for state electricity boards (SEBs) and electricity departments (EDs). Sales of power are used to weight the average. These data are presented in Table C-2.

Table C-2 - Transmission and Distribution Losses for SEBs and EDs - 2002

\begin{tabular}{|c|c|c|}
\hline & $\begin{array}{c}\text { T\&D loss } \\
\%\end{array}$ & $\begin{array}{c}\text { Sale of power } \\
(\mathrm{MkWh})\end{array}$ \\
\hline & $2000-01$ & $2000-01$ \\
\hline & (R.E.) & $(\mathrm{RE})$ \\
\hline \multicolumn{3}{|l|}{ SEBs } \\
\hline Andhra Pradesh & 32.9 & 28418 \\
\hline Assam & 38.6 & 1916 \\
\hline Bihar & 25 & 7897 \\
\hline Delhi & 47 & 9154 \\
\hline Gujarat & 20 & 31435 \\
\hline Haryana & 35 & 10958 \\
\hline Himachal Pradesh & 18.3 & 3268 \\
\hline Jammu\&Kashmir & 56.4 & 2812 \\
\hline Karnataka (KPTCL) & 36.5 & 17276 \\
\hline Kerala & 17.2 & 10700 \\
\hline Madhya Pradesh & 31 & 25571 \\
\hline Maharashtra & 30 & 41598 \\
\hline Meghalaya & 20.3 & 606 \\
\hline Orissa (GRIDCO) & 49.9 & 10822 \\
\hline Punjab & 17.5 & 22385 \\
\hline Rajasthan(Transco.) & 29 & 17686 \\
\hline Tamil Nadu & 16.5 & 33290 \\
\hline UP(Power corp.) & 39.8 & 25310 \\
\hline West Bengal SEB & 30 & 10000 \\
\hline \multicolumn{3}{|l|}{ EDs } \\
\hline Arunachal Pradesh & 34.3 & 102 \\
\hline Goa & 32.9 & 1204 \\
\hline Manipur & 49.9 & 182 \\
\hline Mizoram & 42 & 138 \\
\hline Nagaland & 40.8 & 165 \\
\hline Pondicherry & 14.9 & 1413 \\
\hline Sikkim & 20.1 & 108 \\
\hline Tripura & 38.9 & 419 \\
\hline Total & 29.0 & 314833 \\
\hline
\end{tabular}

The weighted average T\&D loss rate for India is $29.0 \%$. The Government of India is taking steps to address the high rate of losses throughout the power system, and local 
utilities are making efforts to reduce these. One forecast (Planning Commission 2004) predicts that the situation will improve significantly by 2020 , reaching $20 \%$ by that time. Our forecast assumes that the loss rate will decrease linearly over time until it reaches $20 \%$, at which point it will stabilize.

\section{REFERENCES}

GoI (2003). Baseline for renewable energy projects under clean development mechanism. New Delhi, Government of India Ministry of Non-Conventional Energy.

CEA (2002-2003) Indian Central Electricity Authority. Annual issues of General Review Statistics

Planning Commission (2004). India: Vision 2020: Report of the Committee on India Vision 2020, New Delhi

Planning Commission (2002), "Annual report (2001-02) on the Working of State Electricity Boards \& Electricity Departments", Government of India, May 2002 